\title{
Mineralización auro-argentífera hospedada en una brecha hidrotermal en inmediaciones de la Mina La Baja, Distrito Minero de California-Vetas, Santander (Colombia)
}

\section{Gustavo German Contreras Fernández ${ }^{1}$, Carlos Alberto Ríos Reyes ${ }^{1}$, Oscar Mauricio Castellanos Alarcón ${ }^{2}$}

\footnotetext{
1 Escuela de Geología, Universidad Industrial de Santander, Bucaramanga, Colombia

2 Programa de Geología, Universidad de Pamplona, Pamplona, Colombia
}

\section{Resumen}

En el municipio de California, departamento de Santander, se ha desarrollado minería desde épocas de la colonia. Actualmente, una de las tantas labores de explotación que se desarrollaron allí, corresponden a la mina La Baja, en la cual se presenta una mineralización auroargentífera, con una estructura brechificada, perteneciente a un sistema magmático hidrotermal, estructura que no ha sido descrita ni desde el enfoque estructural ni desde el enfoque mineralógico y metalogénico. Por esta razón, este estudio presenta los aspectos geológicos más relevantes sobre la mina La Baja, donde se contextualiza la mineralización que allí se presenta, mostrando sus principales rasgos petrográficos, fases minerales, alteraciones mineralógicas, asociaciones de los minerales de mena y de ganga, el condicionamiento estructural del emplazamiento y propone un modelo preliminar en 3D de la estructura mineralizada.

Palabras clave: brecha hidrotermal, minerales de mena, minerales de ganga, metalogenia, mina La Baja

\section{Gold-silver mineralization hosted in a hydrothermal breccia around the La Baja Mine, California-Vetas Mining district, Santander (Colombia)}

\begin{abstract}
In the municipality of California, department of Santander, mining has developed since colonial times. Actually, one of the many tasks of exploitation that developed there correspond to the La Baja mine, where a gold-silver mineralization occurs, with a brecciated structure that belongs to a magmatic hydrothermal system, which has not been described or from the structural approach or from the mineralogical and metallogenic approach. For this reason, this study presents the most relevant
\end{abstract}


geological aspects of the La Baja mine, where mineralization that occurs there is contextualized, showing its main petrographic features, mineral phases, mineralogical alterations, associations of ore and gangue minerals, structural conditioning of the site and proposes a preliminary 3D model of the mineralized structure.

Keywords: hydrothermal breccia, ore minerals, gangue minerals, metallogeny, La Baja mine

*Para citar este artículo: Contreras Fernández GG, Ríos Reyes CA, Castellanos Alarcón OM. Mineralización auro-argentífera hospedada en una brecha hidrotermal en inmediaciones de la Mina La Baja, Distrito Minero de California-Vetas, Santander (Colombia).Revista Bistua. 2016.14(2):58-80

+ Autor para el envió de correspondencia y la solicitud de las separatas: Ríos Reyes CA . Escuela de Geología, Universidad Industrial de Santander, Bucaramanga, Colombia.e-mail: carios@uis.edu.co

\section{Introducción}

Los depósitos epitermales se encuentran cerca de la superficie y la mineralización se produce a una profundidad máxima de $1 \mathrm{~km}$, pero rara vez más profundo que 600 $\mathrm{m}, \mathrm{y}$, por lo tanto, debido a su poca profundidad, los depósitos epitermales se forman bajo la corteza a temperatura moderada $\left(50-300^{\circ} \mathrm{C}\right)$ y presión intermedia, y comúnmente ocurren en arcos de islas y arcos continentales asociados a un ambiente de subducción (e.g., Bissig and Tosdal, 2009; Sillitoe, 2010). Las mineralizaciones hidrotermales, especialmente auro-argentíferas, actualmente en exploración y explotación en el Distrito Minero de Vetas-California (DMVC), enclavado en el Macizo de Santander y considerado uno de los distritos mineros más importantes del país, son consideradas como formadas en ambientes epitermales (Felder et al., 2005). Según Mantilla et al. (2011), estas mineralizaciones suelen estar hospedadas en una gran variedad de rocas, principalmente metamórficas (de edad Pre-Devónico) e ígneas (de edades Mesozoicas y Cenozoicas). La Mina La Baja se encuentra ubicada en el municipio de California 60 
(Santander), a $55 \mathrm{~km}$ al NE de la ciudad de Bucaramanga, y sus labores de explotación se ubican a $6 \mathrm{~km}$ aproximadamente del casco urbano del municipio de California. Las bocaminas de los túneles donde se desarrolla la actividad minera se encuentran sobre carretera que conduce a la vereda Angosturas (Figura 1). La mineralización auro-argentífera de la Mina La Baja está hospedada en una brecha epitermal, la cual está localizada dentro de una granodiorita de textura porfiríticafanerítica, de edad Triásica perteneciente al Grupo Plutónico de Santander definido por Ward et al. (1973). La mineralización se estudió en el túnel Ventanas, ya que el acceso a otros túneles abandonados hace aproximadamente 15 años no fue permitido. Las reservas medidas totales se desconocen, aunque se considera que representa un depósito de oro-plata epitermal importante en Colombia. El objetivo general del presente trabajo es contribuir al conocimiento del yacimiento auroargentífero presente en inmediaciones de la Mina La Baja, Distrito Minero de California-Vetas (Santander), a partir del estudio de sus características geológicas con el fin de contextualizar geológicamente la brecha hidrotermal mineralizada, que sirva como base para ajustar los programas de desarrollo y producción hacia el futuro.

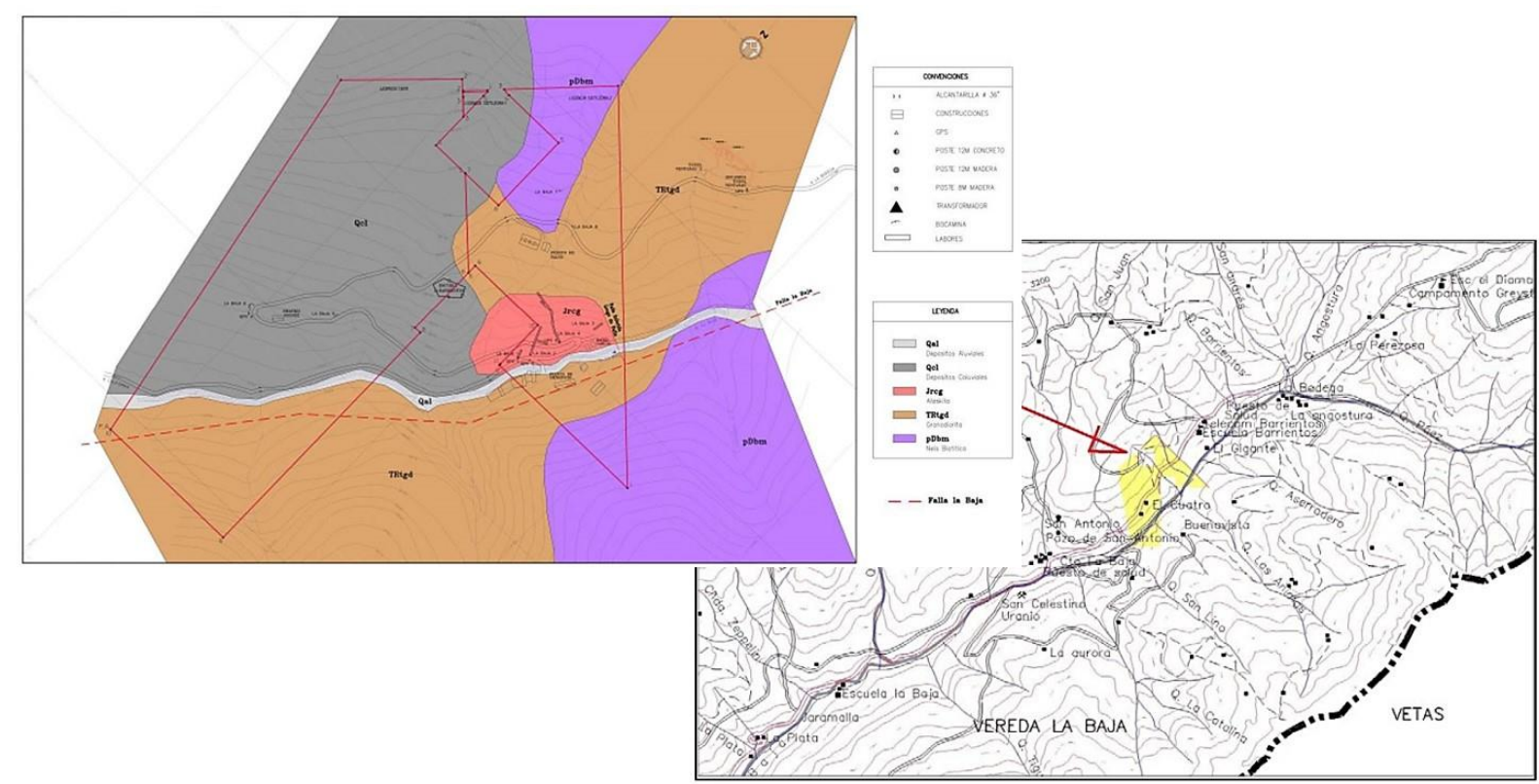

Figura 1. Ubicación del área de la mina La Baja (en amarillo), en el municipio de California. Tomado de IGAC, Plancha 110, modificación personal.

\section{Marco geológico}

La geología regional que se presenta en el área de estudio y sus alrededores es de rocas metamórficas Precámbricas y pre-Devónicas, rocas intrusivas del TriásicoJurásico y rocas intrusivas del Terciario, además de los depósitos Cuaternarios por 
coluvión y aluvión, todas estas rocas pertenecientes al Macizo de Santander. Las rocas ígneas presentes en el área de estudio, correspondientes a plutones de composición granodiorítica y monzogranítica, además de un pórfido que varía de tonalítico a dacítico, pertenecen al denominado Grupo Plutónico de Santander, y junto con las rocas metamórficas del área comprenden el llamado Complejo de Bucaramanga (Ward et al., 1973). Las rocas más antiguas del Macizo de Santander corresponden a las rocas metamórficas del Neis de Bucaramanga. Estas rocas, las cuales se caracterizan por presentar una de estructura néisica, están representadas principalmente por paraneis pelítico, semipelítico y arenáceo, esquisto y cantidades subordinadas de neis calcáreo, mármol, neis horbléndico y anfibolita, aunque también incluye zonas migmatíticas de dos tipos: la primera un paraneis mezclado con roca granítica néisica y la segunda donde aparecen las dos anteriores cortadas por masas pequeñas de granito no foliado de edad más joven (Ward et al., 1973). Según el mismo autor nombrado, quien separa el neis de Bucaramanga en tres fajas, el sector de estudio se encuentra en la faja central, que corresponde al área de los municipios de Berlín-California-Cachirí y los municipios entres esta área. Para Carvajal y Rodríguez (1975), las rocas metamórficas que afloran en el distrito minero de Vetas y California, corresponden a neises biotíticos cuarzofeldespáticos preDevónicas, con textura augen, por lo cual proponen que esta textura se debe al desarrollo de porfidoblastos de feldespato que sufrieron metasomatismo alcalino por la cercanía a un cuerpo leucogranítico que se presenta en la zona, por esa razón ducha textura solo se presenta de manera local, dichas rocas también son afectadas por un intrusivo de carácter granítico hipoabisal de textura porfirítica gruesa que se transforma en porfirítico de grano fino en contacto con las rocas metamórficas, localmente se presentan xenolitos y techos de neises sobre dicho intrusivo. La edad pre-Devónica también es expuesta por Goldsmith et al. (1971), en cuyo trabajo denomina el neis de Bucaramanga el núcleo del Macizo de Santander, como una secuencia gruesa de wacas geosinclinales, shales y probablemente rocas volcánicas metaorfoseadas de alto grado y en parte migmatíticas. Las rocas de la región de California han sido agrupadas en tres conjuntos litológicos, el primero de ellos corresponde a rocas metamórficas de alto grado completamente deformadas y representan las rocas más antiguas de la zona, un segundo grupo o conjunto presenta cuerpos intrusivos, los stocks y rocas porfiríticas, y el último conjunto constituye las rocas sedimentarias del Cretácico al norte de California, esta división fue propuesta por Mendoza y Jaramillo (1979). Los mismos autores subdividen el primer conjunto en dos subconjuntos, el primero de ellos aflora especialmente en las quebradas Páez, Chicagua y La baja, en esta última se encuentra el área de la mina La Baja, sector correspondiente a este estudio, y son rocas migmatíticas paleozóicas, masivas con textura xenoblástica o granoblástica, que contiene neises bandeados a veces de apariencia cataclástica en los que bandas graníticas con plagioclasa, cuarzo, biotita y ortoclasa, alternan con bandas ricas en biotita y en 62 
menor proporción plagioclasa y cuarzo. También presentan localmente sillimanita y plagioclasa parcialmente sericitizada. El segundo subconjunto hace referencia a migmatitas mesozoicas, desarrolladas alrededor de las intrusiones TriásicasJurásicas, presentan textura hipidiomórfica granular con orientación de láminas anhedrales y flexionadas de biotita, los cristales euhedrales a subhedrales y plagioclasa están parcialmente sericitizados, el feldespato potásico anhedral y en parte intersticial presetna ligera argilización, el cuarzo aparece en cristales anhedrales o elongados, se presenta clorita asociada a epídota por la alteración de la biotita. En los alrededores de la quebrada La Baja, aflora el neis migmatítico, en el cauce de las quebradas Angosturas, Las Ánimas, afluentes de la primera, y el camino de la carretera la mina La Bodega, con bandas claras de cuarzo, feldespato potásico, plagioclasa, y bandas oscuras de biotita, y como minerales accesorios magnetita y circón, además de minerales secundarios como sericita y caolín, también se presenta un neis horbléndico en el nacimiento de las quebradas San Juan y San Andrés también afluente de la quebrada La Baja, con hornblenda, plagioclasa, feldespato potásico, cuarzo y piroxeno (diópsido), circón como mineral accesorio, mineral que se encuentra redondeado (detrítico) e incluido en los minerales félsicos, sericita, caolinita y clorita como minerales secundarios (Pinto, 1991). Pérez y Vargas (1993), correlacionan el neis migmatítico con el neis de biotita, cuarzo, feldespato potásico y hornblenda de la faja central de neis de Bucaramanga (Ward et al., 1973), lo describen como un neis que presenta textura schlieren, aflorando en las quebradas San Juan, Chicagua y San Luís, afluentes de la quebrada La Baja, donde se ven pliegues estrechos y deformados en rocas de composición granítica y neísica, lo que indica una mayor movilidad mecánica de ambos cuerpos (Mehnert, 1971 en Pérez y Vargas, 1993), su composición es cuarzo, plagioclasa, feldespato potásico, hornblenda, biotita y sillimanita y accesorios circón, apatito y epidota. Este neis también ha sido denominado, complejo de Bucaramanga (Clavijo y Royero, 2001), y lo describen como paraneis cuarzofeldespáticos, micáceos, hornbléndicos y granatíferos, además de cantidades subordinadas de anfibolita, migmatitas, cuarcitas, mármoles y algunas granulitas. Referente al tipo de metamorfismo que sufrieron este tipo de rocas, hay una variación, Mendoza y Jaramillo (1979), proponen un metamorfismo dentro de las facies de baja presión, concluyen esto por la presencia de minerales como cordierita, sillimanita, andalusita, la escasa cantidad de granate y ausencia de distena, ubican estas rocas en la facies cordierita-anfibolita del tipo abukuma, al igual que Greig et al. (2009) quien propone que el neis fue afectado por varios eventos de deformación y metamorfismo de facies esquistos verdes a anfibolita y Mantilla et al. (2009) anota que estas rocas alcanzaron unas condiciones metamórficas de la facies anfibolita durante la orogenia Grenviliana. La granodiorita de Páramo Rico está compuesta casi en su totalidad de granodiorita que varía a tonalita, de grano medio a grueso, inclusiones oscuras de grano fino, interpretadas como autolitos son comunes, los 63 
minerales máficos tienden a ocurrir en grumos, en California está cortada por cuarzomonzonita, aplita y pórfido curzoso, su composición mineralógica de cuarzo, andesina, hornblenda, biotita y feldespato potásico, accesorios como esfena, apatito y secundarios clorita y epidota (Ward et al., 1973). Varía de masiva a ligeramente neísica, por lo general es holocristalina de grano medio, color moteado con blanco del cuarzo y la plagioclasa y negro de biotita y hornblenda, a veces se presenta mineralizada con sulfuros, principalmente pirita, que se encuenta en venas de cuarzo y epidota, diseminada o esporádicamente asociada a los ferromagnesianos (Mendoza y Jaramillo, 1979). Aflora hacia las partes altas en el extremo suroeste del área de estudio, a lo largo de las quebradas Tiguarí, Catalina y San Luís, afluente de la quebrada La Baja, su composición es cuarzo, plagioclasa, biotita, feldespato potásico, minerales opacos, como minerales accesorios circón, epidota, y secundarios sericita, caolinita y clorita (Pérez y Vargas, 1993). Según Mendoza y Jaramillo (1979), la alaskita es una roca leucogranítica de grano fino a medio, holocristalina, color blanco crema algo manchado y moteado por óxidos de hierro, compuesta por plagioclasa, feldespato potásico, cuarzo, moscovita y biotita, generalmente presenta venilla de cuarzo. A lo largo de la quebrada Chicagua, afluente de la quebrada La Baja, la roca es de color rosado, de grano medio, masiva, foliada y de composición cuarzomonzonita. También se presenta o aflora en las quebradas Páez, La Perezosa y Las Ánimas, todas estas afluentes de la quebrada La Baja, de las primeras tres, en la última aflora con enriquecimiento de cuarzo y pirita, hacia el contacto con las rocas metamórfica se enriquece de biotita, las alteraciones que presenta son silicificación, sericitación, caolinitización y piritización (Pinto, 1991). En las quebradas Tiguari, San Juan, San Luís y Catalina, presenta una composición de cuarzo, feldespato potásico, plagioclasa, opacos, biotita y menos de $1 \%$ de moscovita (Pérez y Vargas, 1993). La edad que se estima para estos granitos pertenecientes al grupo plutónico de Santander, es del JurásicoTriásico, con edades de $172 \pm 6$ y $193 \pm 7$ Ma (Marvin y Mehnert en Ward et al., 1973). Según Ward y Goldsmith (1970), el pórfido que aflora en el área es un pórfido dacítico por su composición, y para Mendoza y Jaramillo (1979) dicho pórfido varía e composición de dacítico a andesítico, y uno de composición granodiorítica este pórfido aflora a lo largo de la quebrada La Baja, desde la quebrada Chicaguá hasta la quebrada Páez con intensa alteración. El pórfido granodiorítico contiene fenocristales de feldespato de hasta $2 \mathrm{~cm}$ de largo y cristales más pequeños de hornblenda y biotita en una matriz muy fina de cuarzo y feldespato con alteración a sericita, mientras el pórfido dacítico-andesítico presenta fenocristales de tamaño variable de feldespato alterado, cuarzo y biotita en una matriz afanítica color gris. Los contactos entre las diferentes rocas y los cuerpos de pórfidos se presentan de forma arbitraria (Mendoza y Jaramillo, 1979). Según Pérez y Vargas (1993), el pórfido dacítico contiene plagioclasa y feldespato potásico en fenocristales de hasta $5 \mathrm{~mm}$ y cuarzo bipiramidal de hasta $1 \mathrm{~cm}$ con alteración a caolín. Mantilla et al. 
(2009) describe el pórfido dacítico con una muestra tomada en la microcuenca de la quebrada La Baja como un cuerpo de color rosado y una textura porfirítica-afanítica donde se reconocen fenocristales de cuarzo bipiramidal, plagioclasa, feldespato potásico y en menor proporción biotita, siendo la plagioclasa y el feldespato potásico los de mayor tamaño, alcanzando 0,5 a $3,5 \mathrm{~cm}$ de espesor. En los primeros estudios se presentaba este cuerpo con una edad post-cretácica por estar intruyendo los cuerpos graníticos del triásico-jurásico (Mendoza y Jaramillo, 1979) y rocas del cretácico (Ward y Goldsmith, 1970), pero actualmente dataciones U-Pb a estas rocas lo ubican en una edad 8,4 $\pm 0,2$ y 9,0 $\pm 0,2 \mathrm{Ma}$ (Mantilla et al 2009). Los depósitos presentes en la quebrada La Baja son de tipo aluvial y terrazas, estos aluviones y bancos de grava gruesa son auríferos y se puede apreciar trabajos rudimentarios en placeres en el sector (Mendoza y Jaramillo, 1979). Las fallas que se presentan en sector del distrito minero de Vetas-California, tienen una tendencia $\mathrm{N}$ a NE, una de ellas es la falla de Cucutilla, falla que se desplaza a lo largo de la quebrada Romeral marcando un lineamiento más notorio hacia el N, su dirección principal viene del NE y se dirige al SW para cruzar el río Vetas y el páramo Rico donde se intercepta con la falla de Charta (Ward et al., 1973). Un ramal de esta falla principal es el que atraviesa la quebrada La Baja, de donde se denomina su nombre como falla de La Baja. Gran parte de los lineamientos fotogeológicos están orientados N-NE, los cursos de las quebradas Chicaguá, San Juan y La Baja corresponden a estos lineamientos (Mendoza y Jaramillo, 1979). Al presentar esta dirección de lineamientos, la falla de La Baja puede ser interpretada como una falla producida por esfuerzos tensionales en un sistema de cizallamiento (Ward y Goldsmith, 1970), las diaclasas tienen una tendencia $\mathrm{N} 50^{\circ}-80^{\circ} \mathrm{W}, \mathrm{N} 50^{\circ}-90^{\circ} \mathrm{E}$ y $\mathrm{N} 0^{\circ}$ $20^{\circ} \mathrm{W}$ con buzamientos $40^{\circ}-90^{\circ} \mathrm{W}$ y $40^{\circ}-80^{\circ} \mathrm{E}$, presentando unos esfuerzos en dirección $\delta 1=\mathrm{N} 45^{\circ} \mathrm{W} / 25^{\circ} \mathrm{SW}, \delta 2=\mathrm{S} 55^{\circ} \mathrm{E} / \mathrm{NE}$ y $\delta 3=\mathrm{S} 48^{\circ} \mathrm{W} / 5^{\circ} \mathrm{NW}$ (Pérez y Vargas, 1993), los filones en algunas excavaciones presentan una tendencia $N 70^{\circ}-90^{\circ} \mathrm{E}$ y $\mathrm{N} 50^{\circ}-70^{\circ} \mathrm{W}$ con buzamientos $50^{\circ}-70^{\circ} \mathrm{NW}$ y direcciones de esfuerzo $\delta 1=\mathrm{N} 70^{\circ} \mathrm{W} / 70^{\circ} \mathrm{NW}, \delta 2=\mathrm{N} 20^{\circ} \mathrm{W} / 70^{\circ} \mathrm{NW}$ y $\delta 3=\mathrm{N} 70^{\circ} \mathrm{E} / 20^{\circ} \mathrm{SE}$ (Aceros y Lamus, 1993). Estructuralmente la mineralización o mineralizaciones que se presentan a lo largo de la quebrada La Baja está controlada por la falla de miso nombre a través de las fracturas que han servido de circulación y depositación de dichos minerales (Bueno, 1955; Carvajal y Rodríguez, 1975), los filones de San Celestino, Píe de Gallo, El Cuatro y La Mascota están relacionados al pórfido que posiblemente estuvo controlado por la falla La Baja (Mendoza y Jaramillo, 1979). A estas fallas se les ha comprobado un movimiento pre y post cretácico (Julivert y Téllez, 1973 en Mendoza y Jaramillo, 1979). La mineralización del municipio de California, no se puede tan solo nombrar un tipo de mineralización en general, puesto que el emplazamiento de la misma no es igual en cada uno de los sectores que comprende el área minera, desde brechas hidrotermales hasta filones mineralizados se encuentran a lo largo de la quebrada La Baja y la vereda Angosturas (Ward y Goldsmith, 1970), con 65 
diferentes tipos de roca caja y de ganga, lo cual permite no solo referirse a una mineralización sino a las diferentes mineralizaciones presentes en dicho municipio. Una de las primeras mineralizaciones descritas en el sector ha sido la del filón de San Celestino (Bueno, 1955), identificado como una brecha hidrotermal que se cementó en el material fracturado por la falla de La Baja. En dicha brecha la paragénesis no se efectuó en una sola fase, sino en varios tiempos sucesivos tanto para la mineralización y la tectónica (Pagnacco, 1962); una primera fase tectónica produce una red de pequeñas fracturas, una primera fase mineralizante está contenida por pirita I, enargita, galena y cuarzo I, una segunda fase mineralizante contiene blenda y tetraedrita (estas dos mineralizaciones fueron masivas), luego en una segunda fase tectónica se forma la falla mayor y la brechadura de los minerales, la tercera fase mineralizante contiene pirita II, marcasita y cuarzo II, y finalmente la alteración y lixiviación que contiene covelina y calcosina. Pagnacco (1962), describe los algunos fragmentos de la brecha como fragmentos de pórfido y concluye que las mineralizaciones del filón de San Celestino fueron producidas por el batolito que causó la formación del pórfido ácido de California. Ward y Goldsmith (1970) asocian las mineralizaciones de las minas San Celestino, La Catalina y La Mascota por minerales presentes como calcopirita, covelina, bornita, esfalerita, galena, rara vez molibdenita y uraninita en San Celestino. EL oro en estas minas está asociado a las cantidades considerables de molibdeno, tungsteno, cobre, plomo y zinc. El filón conocido como La Francia, fue descrito por Carvajal y Rodríguez (1975), su mineralización está contenida por cuarzo, pirita, galena argentífera y esfarelita, el cuarzo se presenta en varias generaciones tanto criptocristalino como anhedral, la pirita pudo haber sido formada por el proceso de alteración de los minerales ferromagnesianos, donde se desprendió hierro y se combinó con azufre por los fluidos mineralizantes. Para estos autores es posible que las soluciones hidrotermales que depositaron los filones provienen de fuentes magmáticas residuales de la cristalización de los pórfidos tonalíticos, y que estos fluidos tenían abundante cantidad de azufre y $\mathrm{CO}$ responsables de la alteración hidrotermal presente. Mendoza y Jaramillo (1979), describen las mineralizaciones con contenido de pirita, galena, esfarelita, tetraedrita, marcasita, enargita y calcopirita, en algunos sectores se presenta reemplazamiento total de galena por blenda y tetraedrita. El cuarzo es de tipo criptocristalino tiene apariencia de calcedonia y está asociado localmente con adularia, alunita y sulfuros. La presencia de alunita en los filones de cuarzo sin molibdeno, sugiere que se trata de alunita supergénica. Un estudio de las alteraciones en el sector, propone cuatro diferentes paragénesis de alteraciones, la primera es caolinítica, con minerales como caolín, alunita, jarosita y cuarzo, la segunda es sericítica, con sericita y cuarzo, una tercera es la propilítica con clorita y epidota, por último la silicificación y piritización, siendo esta la más importante de los yacimientos (Polanía, 1983). En la mina La Bodega se presenta una asociación mineral de cuarzo, pirita como mayor sulfuro rico en oro y plata, alunita por la 66 
oxidación de la pirita y hacia la mina La Baja se encuentran estos mismos con esfarelita, galena y tetraedrita (Pinto, 1991). La presencia de alunita sugiere un fluido con contenido apreciable de concentraciones de sulfato, como alteraciones de venas en rocas graníticas (e.g., Barnes, 1979 en Pinto, 1991). Pérez y Vargas (1993), proponen tres fases mineralizantes para la mina San Cayetano, la primera de ellas con pirita, galena y cuarzo, una segunda con cuarzo, esfarelita, pirita y calcopirita y una última con cuarzo, pirita y marcasita, además describen cinco alteraciones presentes, una fílica con cuarzo, pirita y sericita, la propílica con clorita, epidota, calcita, zoisita, zeolita, caolinita, sericita y pirita, la argílica con illita, montmorillonita, helloysita, cuarzo y calcita, la argílica avanzada con alunita, caolinita, dickita, diáspora y pirofilita, por último la oxidación con gohetita, hematita y jarosita. De esto se destaca la zona propílica no fue avanzada por la presencia de zeolitas (gismondina y despuljosita). En el depósito Angosturas, se han descrito cuatro diferentes tipos de menas auroargentíferas, la primera de ellas tiene dos paragénesis diferentes, una con oro, plata, pirita, tetraedrita, telurio y marcasita, y otra con oro, plata, tetraedrita y digenita, la tercera. La segunda mena contiene una paragénesis con oro, plata, pirita, calcopirita, tetraedrita, arsenopirita y bornita, otra paragénesis con oro, plata pirita, calcopirita, digenita, tetraedrita y enargita. Una tercera mena contiene una paragénesis de oro, plata y pirita. La última mena presenta una primera paragénesis con pirita, calcopirita y una segunda paragénesis con limonita, ilmenita y magnetita (Díaz y Guerrero, 2006). El control de estas mineralizaciones, está asociado a un control estructural con una estrecha relación al pórfido (Mendoza y Jaramillo, 1979), esto esta baso en que los principales filones de California se localizan en dirección del stock de pórfido granodiorítico de La Baja, las zonas de intensa alteración hidrotermal son frecuentes en los alrededores de pequeñas masas de roca porfirítica. Esta depósito ha sido encajado en un depósito de categoría "vein type", y genéticamente como un yacimiento de origen magmático o magmático de tipo hidrotermal de termal medio a bajo (e.g., Pinto, 1991; Pérez y Vargas, 1993).

\section{Trabajo de campo, muestreo y métodos analíticos}

El trabajo de campo se realizo en dos fases, la primera para desarrollar la geología local en inmediaciones de la mina La Baja y la segunda para identificar la mineralización del túnel Ventanas. La primera fases se realizó por un lapso aproximado de dos semanas, para desarrollar una cartografía local del área de estudio, con recolección de muestras para análisis petrográfico y toma de datos estructurales y descriptivos, recorriendo no solo el área correspondiente la mina La Baja, sino también su alrededores, esto para reconocer las unidades litológicas que se presenta en el sector, además de identificar la o las posibles rocas caja donde se 67 
emplaza la mineralización. Para poder desarrollar esta cartografía local, se recorrió el camino o carreteable principal desde cercanías de la mina El Cuatro hasta la mina La Bodega, pasando por la mina La Baja, los caminos que se presentan hacia las fincas y hacia el cerro El Violetal y algunas quebradas aledañas como la quebrada de Las Ánimas. La segunda fase se programó un mes después de la primera, con el fin de realizar una cartografía detallada del área de la mina y del túnel Ventanas, además de tener en cuenta sus mineralizaciones. Para el desarrollo de esta salida fue necesario dedicar un tiempo específico a la toma de datos y recolección de muestras del túnel Ventanas, que es donde actualmente se desarrolla la explotación por parte de la SOCIEDAD MINERA LA BAJA S.A.S., y otro tiempo para la toma de datos y recolección de muestra alrededor de las antiguas explotaciones de la mina La Baja, que como se dijo antes, están abandonadas y no es permitido el acceso a dichos túneles. En el túnel Ventanas, se recorrieron los niveles 2 y 3 , pues el 1 nivel se encuentra tapado a causa de caída de las paredes que lo soportan, lo cual impide su estudio. Del nivel 2 se tomaron datos estructurales y descriptivos, recolección de muestras en cada una de las clavadas o traviesas donde se realizaron frentes de explotación, frentes que en la actualidad se encuentran detenidos en su explotación por decisiones técnicas por partes de quienes dirigen la explotación por lo cual este nivel solo presenta un frente explotación denominado frente 3 . En el nivel 3, se encuentran los frentes de explotación 1 y 2 , cada uno de ellos con una clavada 0 traviesa que pretenden conectar con el nivel 2. Como el túnel Ventanas presenta una mineralización que los mineros que realizan la explotación denominan bolsón (no han encontrado roca caja pues la mineralización continua hacia todos los lugares que han decidido explotar dentro del túnel), los datos estructurales y descriptivos y la recolección de las muestra de mayor interés tomadas dentro del túnel fueron las de los frentes 1,2 y 3 , pues solo en estos frentes se presenta la asistencia técnica de luz y espacio necesario y adecuado, y solo allí se puede corroborar la expansión o extensión de la mineralización. Con respecto a la geología y mineralización del sector de explotación antiguo de la mina La Baja, se realizó un recorrido por toda el área de tal manera que se obtuviera una cantidad de datos y muestras representativas. Como los túneles donde se desarrollaba anteriormente las explotaciones de la mina La Baja están en abandono y con impedimento para ingresar, se tomaron datos estructurales y descriptivos y recolección de muestras para identificar la geología y posibles mineralizaciones alrededor de estos. La tercera fase fue la de mayor duración, pues en esta se contemplan la preparación de las muestras y el análisis o caracterización de las mismas. El análisis petrográfico realizado para las muestras en esta etapa es mineralógico, a través de 6 secciones delgadas y 4 secciones pulidas (Tabla 1), realizadas en el laboratorio de preparación de muestras de la Escuela de Geología de la UIS, con el proceso estándar a seguir para la realización de las mismas, corte de la muestra que se decidió analizar en una cortadora marca Minosecar 2 ROW-RATHENO, secado en mufla, nivelado en una 68 
pulidora devastadora marca BUEHLER, pegado de placa de vidrio, y nivelado final hasta 3 micras con abrasivo 400 hasta 1000, esto para las secciones delgadas; para las secciones pulidas, luego de nivelar la cara que se decidió analizar, se pule en una pulidora de paño marca MONTASUPAL hasta obtener el resultado querido. Las secciones delgadas se analizaron en el laboratorio de microscopía óptica de la Escuela de geología de la UIS, en microscopios marca Nikon que contiene objetivos de $5,10,20$ y 40X, y permite la toma de fotos por cámara integrada. El análisis calcográfico de secciones pulidas se llevó a cabo en un microscopio de luz reflejada marca Nikon del Laboratorio de Petrografía del Grupo de Investigación en Geología Básica y Aplicada (GIGBA) de la sede UIS-Guatiguará. Se decidió como técnica de análisis químico, el método de difracción de rayos $X$, técnica que permite de manera cualitativa y cuantitativa la obtención o conocimiento de todos los minerales presentes en una muestras, sobre todos aquellos que están en menor proporción y no se pueden identificar en sección delgada, además de tener mayor precisión en el análisis cuantitativo. En total se tomaron 6 muestras representativas para realizar dicho análisis, la preparación de las muestras para dicho análisis se llevó a cabo en el laboratorio de triturado de la Escuela de Geología de la UIS, en una trituradora de mandíbulas Retsch, luego de obtener la muestra triturada, se pasó por un mortero de AGATA para llevarlas a un tamaño de 38um (400mesh), necesario para el análisis por difracción de rayos $\mathrm{X}$, el cual se llevó a cabo en el Laboratorio de Rayos $X$ de la Escuela de Química de la UIS, en un difractómetro de polvo marca PANalytical modelo X'PERT PRO MPD bajo las siguientes condiciones: Voltaje $45(\mathrm{kV})$, Corriente 40(mA), Rendijas Soller 0.04 rad (Incidencia y Difracción), Rendijas Fijas $1 / 4$ y $1 / 8$ (Incidencia) y $1 / 4$ (Difracción), Muestreo $0.013^{\circ}$ 2theta, Rango de Medición 4-70 2theta, Radiación, Filtro Ni, Detector de estado sólido referencia PIXcel con 255 canales activos, Tipo de barrido Continuo, Tiempo por paso 59 segundos. El análisis cualitativo de las fases presentes en la muestra, se realizó mediante comparación del perfil observado con los perfiles de difracción reportados en la base de datos PDF-2 del International Centre for Diffraction Data (ICDD). El análisis cuantitativo de las fases encontradas se realizó mediante el refinamiento por el Método de Rietveld del perfil observado, habiéndole agregado a la muestra una cantidad conocida de un estándar interno (Aluminum oxide, 100mesh, 99\%. Corundum -phase. Aldrich No. 23,474-5) correspondiente al $20 \%$. Finalmente, luego de analizar y discutir la información generada en las fases anteriores se realizó el diseño preliminar del yacimiento en el software AUTO-CAD 2010, donde se ubican en plano 2D la cartografía y mineralización del área, identificando cada una de las diferencias que presenta el yacimiento. Con el mismo software, se utiliza la herramienta o se implementa la herramienta de proyección en 3D, que se realiza luego de aplicar las respectivas actualización y corrección de curvas de nivel o topografía correspondiente al área, con esta herramienta es posible modelar profundidades, contactos y espesores desde las diferente 69 
perspectivas que permite dicha dimensión, este modelo preliminar se realizó con el fin de mostrar el posible condicionante espacial de la mineralización. Para realizar este diseño preliminar y utilizar las herramientas correspondientes del software AUTO-CAD 2010, fue necesaria la asistencia del profesional en diseño de dimensiones Yurlewinson Mantilla, quien ofreció su conocimiento y experiencia en la dirección del diseño.

\section{Geología del área de estudio}

La geología que se presenta a continuación, fue obtenida en las salidas de exploración en campo, realizadas en el área de la mina La Baja y sus alrededores. En el caso de la descripción geomorfológica del área de la mina La Baja, es necesario tomar en cuenta la geomorfología que presenta toda la zona que recorre la quebrada La Baja, pues la licencia de esta mina se encuentra en medio de dicha afluente. La geoforma general que se evidencia en el recorrido de la quebrada La Baja es de tipo encañonada, ya que fluye en el sector, de norte a sur desde la vereda Angosturas hasta su encuentro con el río Vetas, atravesando las paredes que se levantan al este y oeste encerrando el paisaje de forma abrupta (Figura 2a). El lineamiento que se evidencia a consecuencia de la falla de La Baja, es el que ha permitido este tipo de geoformas, pues es notorio que las paredes a lado y lado se han levantado en torno a este plano de falla, proporcionando pendientes en forma de $v$, típica de paisajes formados por rocas cristalinas, siendo más escabrosas al este que al oeste en este caso. Aunque la geoforma que se observa con mayor facilidad es el encañonamiento, Galvis (1998) propone que el distrito minero de CaliforniaVetas está dentro de una caldera volcánica de aproximadamente $10 \mathrm{~km}^{2}$, dicha caldera presenta sus paredes rodeando ambos distritos, pues el cono volcánico de que le suprayacía colapsó y erosionó, dejando solo las huella de la caldera. Además de proponer esta geoforma en el sector, también anota que el cerro El Violetal, es el cono resurgente de esta caldera o antiguo volcán, cerro que se encuentra ubicado casi en la mitad de dicha caldera (Figuras 2b-2f). 

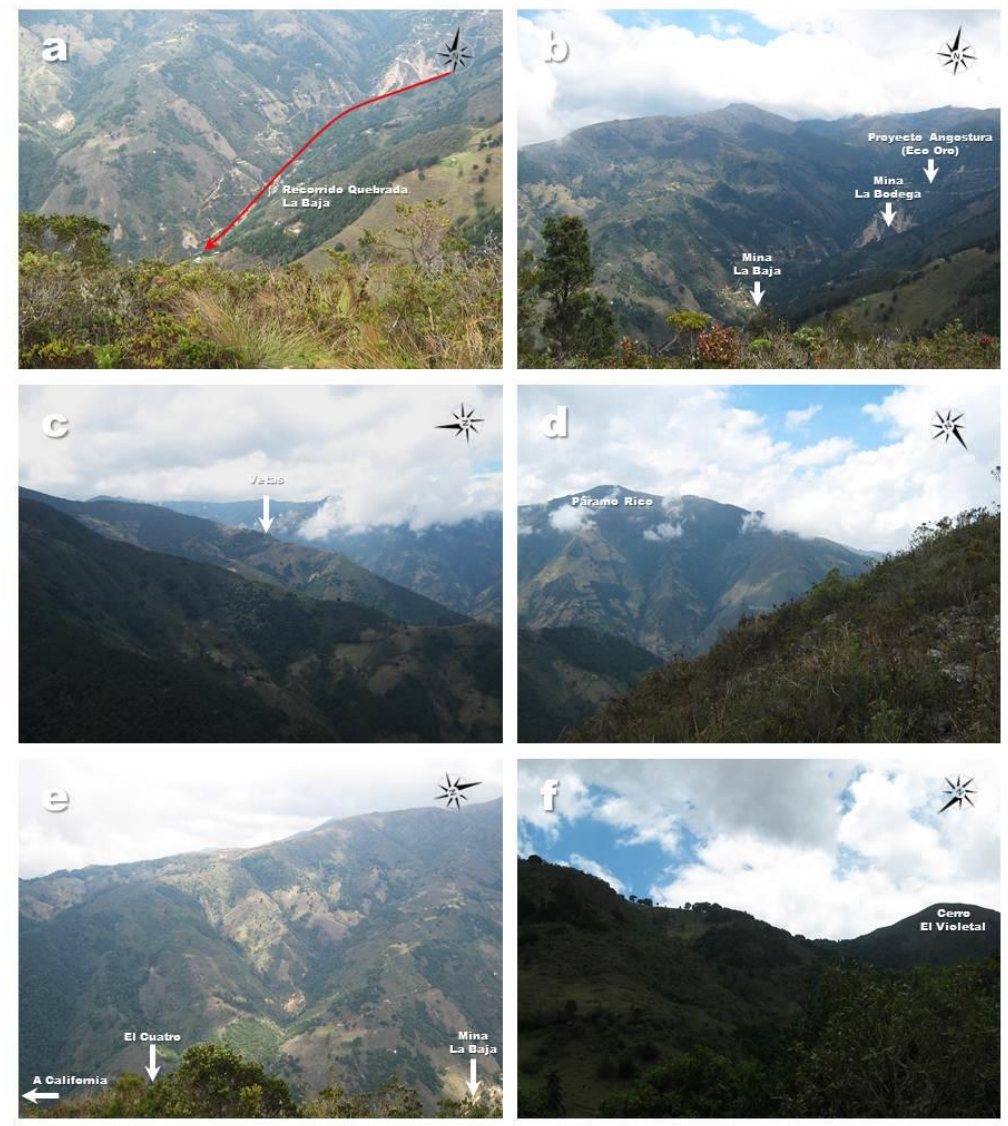

Figura 2. Rasgos geomorfológicos. a) Geoforma encañonada que recorre la quebrada de La Baja, sector en el cual se presenta la mineralización auroargentífera del municipio de California. b) Paredes de la posible caldera volcánica, al fondo Angosturas. c) Paredes de la posible caldera volcánica, al fondo Vetas. d) paredes de la posible caldera volcánica, al fondo Páramo Rico. e) Paredes de la posible caldera volcánica, al fondo el cuatro. f) Cerro El Violetal, cono resurgente del paleovolcán, tomado desde la bocamina del túnel Ventanas.

Teniendo en cuenta estas dos geoformas principales, el área de la mina La Bodega hace parte tanto de la caldera volcánica como de cañón de la quebrada La Baja, pues hacia el oeste se encuentra parte de su alinderación respectiva, donde se levantan algunas de las paredes de posible paleovolcán, además que al este de la alinderación está la base topográfica del cerro El Violetal, y es atravesada por la quebrada de La Baja, quedando ubicada en la mitad de este cañón. Cabe anotar que la mineralización del municipio de California solo se presenta o hasta el momento solo se ha descubierto desde el cañón de la quebrada La Baja hasta la vereda Angosturas. La mineralización del área de la mina La baja, se encuentra al igual que las mineralizaciones de todo el sector en sus alrededores, condicionada estructuralmente por la falla de La Baja, falla que es evidenciable por el lineamiento que presenta la quebrada que lleva su nombre, lineamiento que mantiene una dirección NE, siendo esta satélite de la falla regional de Cucutilla. 
71

Dicho condicionamiento fue reconocido por Mendoza y Jaramillo (1979), además de otros estudios del sector, que enmarcan un condicionamiento estructural en las mineralizaciones, específicamente en las brechas hidrotermales de San Celestino, El cuatro, La Francia y Mascotas (e.g., Bueno, 1955; Carvajal y Rodríguez, 1975;

Mendoza y Jaramillo, 1979; Aceros y Lamus, 1993). Otras fallas en el sector que posiblemente esta relacionadas con las brechas mineralizadas, pues están en la misma dirección de las mineralizaciones brechificadas y son satélites de la falla de la Baja, son la falla de Sisavita, las fallas correspondientes a las quebradas Móngora y La Venta (Galvis, 1998), y la falla de Angosturas (Díaz y Guerrero, 2006). Todas estas mineralizaciones de tipo brecha hidrotermal, tiene un direccionamiento del emplazamiento en sentido SE, sentido perpendicular a la dirección de la falla La Baja, de igual forma, la brecha hidrotermal que se presenta en el túnel Ventanas, tiene un direccionamiento en el emplazamiento en sentido SE, constituyéndose posiblemente como una brecha condicionada estructuralmente por la falla de La Baja. En las labores de explotación, la mineralización presentan tres familias de diaclasas, una principal con dirección $\mathrm{N} 20^{\circ}-30^{\circ} \mathrm{E} / 40^{\circ}-50^{\circ} \mathrm{SE}$ que se evidencia constantemente en el techo de los túneles distanciadas cada 5 a 8 metros, y dos secundarias con dirección N $45^{\circ}-70^{\circ} \mathrm{W} / 35^{\circ} 40 \mathrm{NE}$ y N $45^{\circ}-65^{\circ} \mathrm{W} / 50^{\circ}-60^{\circ} \mathrm{SW}$ (Figura 3a y Tabla 1). Al ser las familias de diaclasa principales las más consecuentes y constantes, es posible que la dirección de emplazamiento sea esa misma dirección. Una tercera razón para creer que esta brecha está condicionada estructuralmente, es la continuidad que han presentado en los frentes de explotación, los cuales han encontrado roca caja hacia el NW, mientras su profundización o clavadas de nivel se siguen adelantando en sentido SE. Con el fin de verificar la continuidad de la mineralización, se realizó un segundo túnel de laboreo a 60-70 metros al W de la bocamina del túnel Ventanas, a este segundo laboreo se le denominó túnel Ventanas 2 de aproximadamente de 15 metros de profundidad en dirección NW, pero no se consiguió dicha mineralización, por lo cual se cree que el espesor de la brecha no supera los $100 \mathrm{~m}$ de diámetro, y su extensión aumenta solo en el sentido de su buzamiento. En general el sentido estructural del sector donde se presentan las mineralizaciones auroargentíferas del municipio de California (Santander), corresponde a un sistema de esfuerzos tensionales o sistema compresivo (Ward y Goldsmith, 1970), donde se evidencias planos de cizallamiento y en algunos sectores como en la mina de La Bodega zonas de "gauge" de falla (Galvis, 1998), al igual que en el área de la mina La Baja, en esta última, es posible observar el plano de falla perpendicular al lineamiento que presenta la falla de La baja (Figura 3b). 

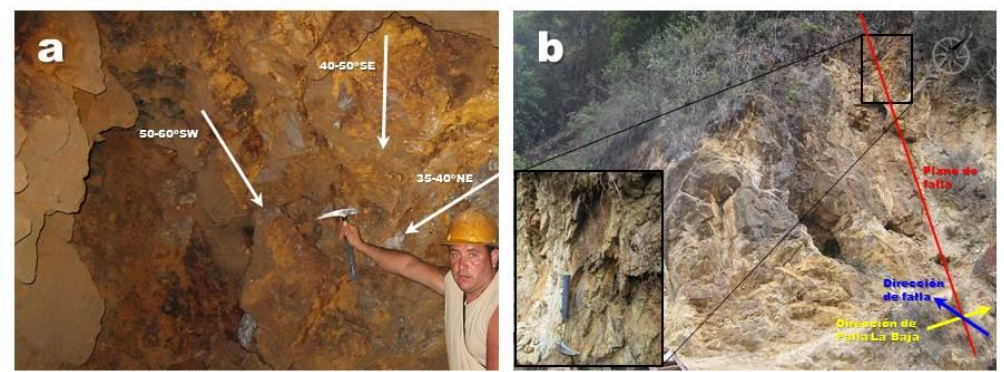

Figura 3. Estructuras en el túnel Ventanas. a) Principales familias de diaclasas presentes en la mineralización tipo brecha hidrotermal, del túnel Ventanas, frente de explotación 2. b) Falla local perpendicular a la falla de La Baja, se puede observar en el recuadro una zona de "gauge" de falla.

Tabla 1. Familias de diaclasas tomadas en los labores de explotación del túnel Ventanas, brecha hidrotermal.

\begin{tabular}{cccc}
\hline Diaclas a & Familia 1 & Familia 2 & Familia 3 \\
\hline 1 & $\mathrm{~N} 30^{\circ} \mathrm{E} / 46^{\circ} \mathrm{SE}$ & $\mathrm{N} 45^{\circ} \mathrm{W} / 36^{\circ} \mathrm{NE}$ & $\mathrm{N} 60^{\circ} \mathrm{W} / 51^{\circ} \mathrm{SW}$ \\
2 & $\mathrm{~N} 29^{\circ} \mathrm{E} / 40^{\circ} \mathrm{SE}$ & $\mathrm{N} 53^{\circ} \mathrm{W} / 36^{\circ} \mathrm{NE}$ & $\mathrm{N} 45^{\circ} \mathrm{W} / 55^{\circ} \mathrm{SW}$ \\
3 & $\mathrm{~N} 20^{\circ} \mathrm{E} / 42^{\circ} \mathrm{SE}$ & $\mathrm{N} 48^{\circ} \mathrm{W} / 35^{\circ} \mathrm{NE}$ & $\mathrm{N} 63^{\circ} \mathrm{W} / 55^{\circ} \mathrm{SW}$ \\
4 & $\mathrm{~N} 28^{\circ} \mathrm{E} / 50^{\circ} \mathrm{SE}$ & $\mathrm{N} 70^{\circ} \mathrm{W} / 36^{\circ} \mathrm{NE}$ & $\mathrm{N} 58^{\circ} \mathrm{W} / 55^{\circ} \mathrm{SW}$ \\
5 & $\mathrm{~N} 23^{\circ} \mathrm{E} / 40^{\circ} \mathrm{SE}$ & $\mathrm{N} 62^{\circ} \mathrm{W} / 40^{\circ} \mathrm{NE}$ & $\mathrm{N} 47^{\circ} \mathrm{W} / 50^{\circ} \mathrm{SW}$ \\
6 & $\mathrm{~N} 28^{\circ} \mathrm{E} / 41^{\circ} \mathrm{SE}$ & $\mathrm{N} 63^{\circ} \mathrm{W} / 35^{\circ} \mathrm{NE}$ & $\mathrm{N} 65^{\circ} \mathrm{W} / 58^{\circ} \mathrm{SW}$ \\
7 & $\mathrm{~N} 30^{\circ} \mathrm{E} / 47 \mathrm{SE}$ & & $\mathrm{N} 63^{\circ} \mathrm{W} / 60^{\circ} \mathrm{SW}$ \\
8 & $\mathrm{~N} 20^{\circ} \mathrm{E} / 46^{\circ} \mathrm{SE}$ & & \\
9 & $\mathrm{~N} 28^{\circ} \mathrm{E} / 40^{\circ} \mathrm{SE}$ & & \\
10 & $\mathrm{~N} 25^{\circ} \mathrm{E} / 41^{\circ} \mathrm{SE}$ & & \\
\hline
\end{tabular}

La litoestratigrafía que se presenta a continuación ha sido contextualizada con los trabajos previos que se han realizado en el sector, por lo cual se tendrán en cuenta los nombres ya establecidos para las rocas que afloran en dicha zona. Las rocas más antiguas que afloran en el área de la mina La Baja, corresponden a rocas metamórficas, de estructura néisica que por su composición se denomina neis biotítico, y se encuentran al norte de la concesión sobre la vía que conduce a la vereda de Angosturas (Figura 4a), y al este y de la concesión sobre el camino de herradura junto a la quebrada La Baja hacia la quebrada El Aserradero (Figura 4c). Aunque abarca una pequeña extensión dentro de los límites de la alinderación correspondiente a la mina La Baja, se extiende hacia el sector del túnel Ventanas que pertenece a la mina La Bodega pero que se encuentra con permiso de explotación por parte de la mina La Baja, como se mencionó en las generalidades de este estudio. En el afloramiento es evidenciable su estructura néisica, sus bandas en

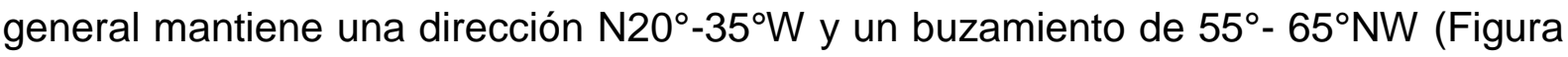
4c). La alteración de la plagioclasa a sericita y de la biotita a clorita, es evidente tanto en muestra de mano como en sección delgada y las fracturas que presenta la 72 
73

roca, se han rellenado posiblemente por minerales de sulfuros que han sido alterados por el intemperismo (Figura 4b). Este neis biotítico es correlacionable con el neis migmatítico encontrado en la leyenda de la geología del sector, del cual se habla en el marco teórico de este estudio, por tal razón se ha dicho que cronológicamente son las rocas más antiguas que afloran en el área de la mina La Baja, y el metamorfismo que las afectó es de tipo regional, de facies anfibolita en la orogenia Grenvilinana (Mantilla, 2009). Las rocas ígneas son las de mayor presencia en el área de la mina La Baja, todas estas a manera de plutones o rocas intrusivas, es el caso de la granodiorita que aflora hacia el este del sector de estudio, en el túnel ventanas, siendo esta la roca caja en el sector de la mineralización de dicho túnel, en el centro-este, se extiende por el camino de herradura junto a la quebrada La Baja, allí se observan una estructura en forma de diques (Figura 4e), en la vía que comunica la mina La Baja con la vereda Angosturas se puede apreciar el contacto entre le neis biotítico y este granito (Figura 4d); hacia el sur se encuentran afloramientos de este intrusivo, tanto en el casino que pertenece a la mina La Baja, como la quebrada de Las Ánimas, donde se puede ver atravesada por venas de cuarzo horizontal y verticalmente (Figura 4f). La roca presenta una textura fanerítica, en su mayoría equigranular, masiva, en muestra de mano es apreciable la alteración a sericita y en algunos sectores a clorita. Con base en estos datos y realizando la comparación con los estudios previos de la región, es posible correlacionar esta granodiorita con la granodiorita de edad Triásico que se encuentra en la leyenda de la geología del sector, pues estas contienen similitudes en la mayoría de sus datos y características identificadas. 

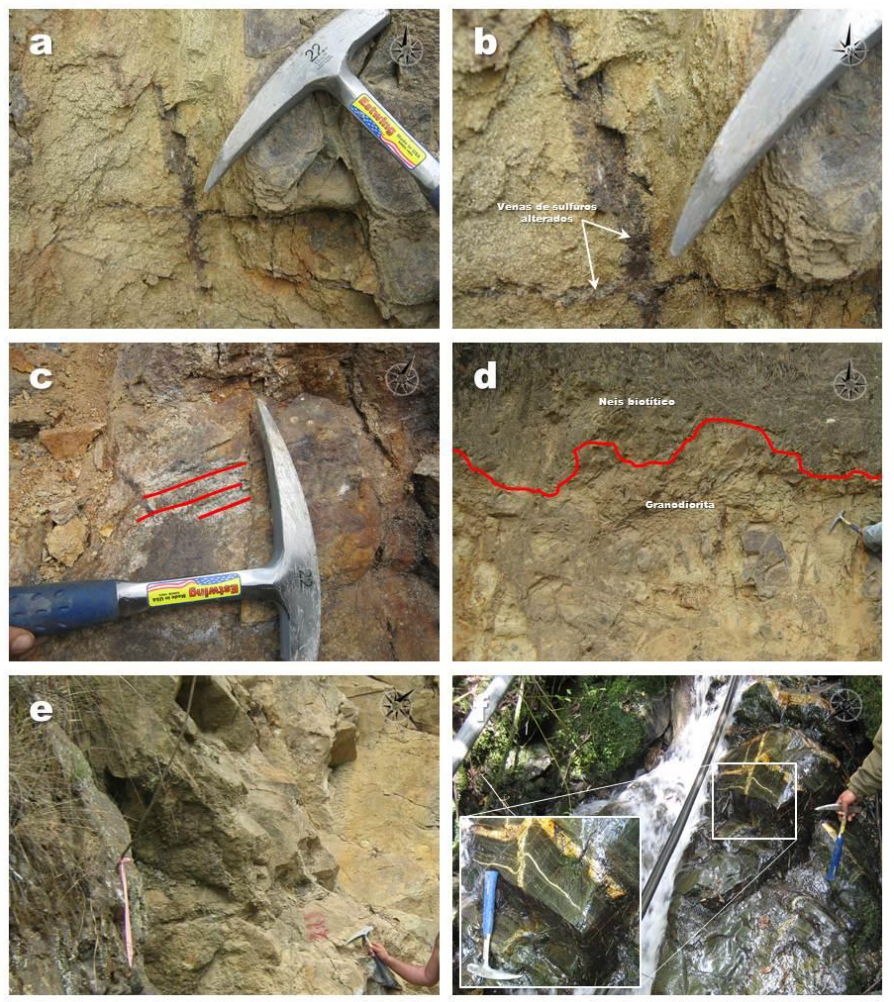

Figura 4. Roca metamórfica, neis biotítico. a) Afloramientos sobre la vía que comunica la mina La Baja con la vereda Angosturas. b) Alteración a sericita y clorita, además de fracturas rellenas por sulfuros también alterados. c) Afloramiento sobre en camino de herradura junto a la quebrada La Baja, bandeamiento en rojo. Roca ígnea, granodiorita. d) Contacto entre el neis biotítico y la granodiorita sobre la carretera que conduce de La Baja a la vereda Angosturas. e) Afloramiento sobre la el camino de herradura junto a la quebrada La Baja, se puede apreciar la estructura en diques. f) Afloramiento sobre la quebrada Las Ánimas, atravesada por venas de cuarzo (recuadro en aumento).

Un segundo granito que se encuentra en el sector de la mina La Baja, es una alaskita, este aflora específicamente en el centro del área de la mina La Baja, en la vía que comunica a esta hacia la vereda Angosturas, en las antiguas labores de explotación de esta mina, frente a las instalaciones de la planta de beneficio (Figura 5a). El leucogranito, está en contacto con la granodiotira, en el camino de herradura junto a la quebrada de La Baja (Figura 5b), este contacto se presenta fallado con evidencia de un "gauge" de falla en el plano de contacto (Figuras 5c-5d). Este leucogranito o alaskita se correlaciona con la alaskita descrita en la leyenda de los estudios previos de la región, por lo cual su ubicación cronoestratigráfica concurriría de edad Jurásica. En el sector de la mina La Baja, los depósitos cuaternarios que se presentan son de tipo aluvión y coluvión. El primero de ellos presenta depositación continua por el efecto de la quebrada La Baja y sus afluentes, dicho depósito se encuentra atravesando el área de nororiente a suroccidente, siguiendo el recorrido de la quebrada nombrada, con cantos de hasta un metro de espesor a lado y lado de 74 
la quebrada (Figura 5e). Los depósitos de coluvión, no solo se encuentran a orillas de la quebrada La Baja, sino a través de la vía que comunica al municipio de california con la vereda Angosturas, en el área de la mina La baja, se encuentra aflorando estos depósitos desde las instalaciones de la planta de beneficio de INGEOMINAS hasta la escuela Barrientos, cubriendo una gran parte del terreno estudiado, especialmente hacia suroccidente, alcanzando espesores de hasta 10 metros de altura (por lo menos hasta donde se puede apreciar, Figura 5f), con cantos de hasta 5 metros de diámetro. En algunos sectores esta remoción en masa sigue en actividad, sin descartar que los sectores que se han estabilizado, vuelvan a activarse, esto debido a la falta de mantenimiento de los taludes y las pendiente enmarcadas del todo el sector.
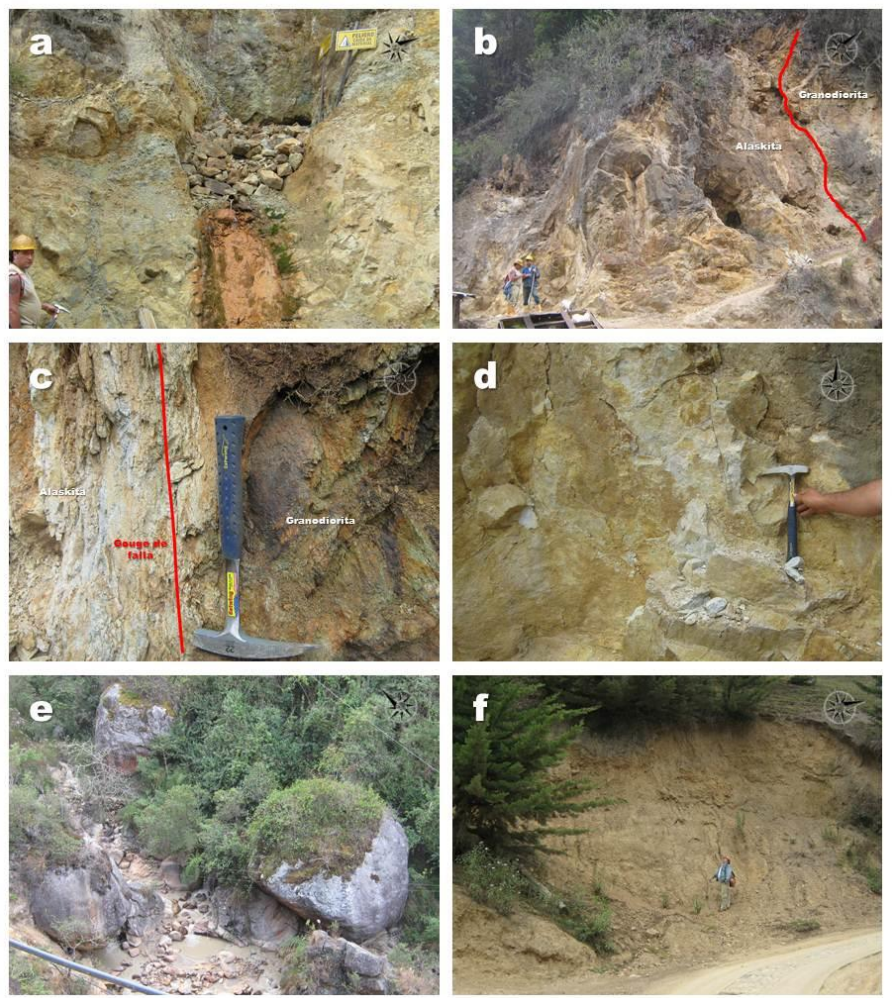

Figura 5. Roca ígnea, alaskita. a) Afloramiento en las antiguas labores de explotación de la mina La Baja. b) Contacto entre las rocas ígneas (línea roja), granodiorita y alaskita, en el camino de herradura junto a la quebrada La Baja. c) Contacto fallado entre las rocas ígneas, granodiorita y alaskita, en el plano en rojo se aprecia el "gauge" de falla. d) Afloramiento en la cual se puede apreciar el color claro característico de esta roca para ser llamada así. Depósitos cuaternarios. e) Aluviones de la quebrada La Baja, también se puede observar cantos de más de 5 metros de diámetro por caída de rocas. f) Coluviones de hasta 10m de espesor, en la vía que comunica la mina La Baja con la vereda Angosturas. 
76

\section{Caracterización de la mineralización}

\section{Roca encajante}

Por descripción en sección delgada, el neis biotítico está compuesto por minerales principales como cuarzo, plagioclasa, biotita, moscovita, feldespato potásico, minerales secundarios como clorita (de la biotita), sericita (de la plagioclasa) y caolín (del feldespato potásico), y minerales accesorios como circón y corindón. En las placas se pueden apreciar las biotitas y moscovitas alineadas, los minerales de cuarzo, plagioclasa y feldespato potásico alargados, típico de los esfuerzos que produjeron el metamorfismo (Figura 6a). Las texturas que presenta este neis biotítico es lepidogranoblástica y poiquiloblástica, la foliación es continua (Figura 6b), la posible paragénesis de la roca es cuarzo + plagioclasa + biotita + moscovita, posicionándolo en un metamorfismo regional de facies de la anfibolita. Aunque no hace parte de la paragénesis de la roca, el circón es el mineral accesorio presente en esta roca, y se observa generalmente relacionado con la plagioclasa y el cuarzo (Figura 6c). En el caso de la granodiorita, los minerales principales que componen la roca son cuarzo $(18-20 \%)$, plagioclasa $(45-50 \%)$, feldespato potásico $(8-10 \%)$, hornblenda (10-15\%), biotita (8-10\%); minerales menores como moscovita, epidota, clinozoicita y opacos, minerales accesorios como esfena y apatito, y minerales secundarios como clorita (de biotita y hornblenda), sericita (de plagioclasa) y caolín (de feldespato potásico) (Figuras 6e y 6f). En algunos sectores, la roca presenta una epidotización a manera de vena, generalmente sobre los cristales de plagioclasa y feldespato potásico, que recorre la muestra sin ninguna dirección preferencial (Figuras $7 \mathrm{a}$ y $7 \mathrm{~b}$ ), también esta presenta clinozoicita como variedad de la epidota (Figura 6d). Otra de las texturas que presenta la roca, es de intercrecimiento, no de manera general sino local, una de estas es la poikilítica, que en este caso son cristales de biotita incluidos en cristales de hornblenda (Figuras $7 \mathrm{c}$ y $7 \mathrm{~d}$ ). La roca corresponde a una granodiorita, la cual presenta plagioclasa (65-75\%), cuarzo (20$25 \%$ y feldespato potásico (10-15\%). La alaskita mineralógicamente, está compuesta por cristales principales de cuarzo (30-35\%), feldespato potásico (15$20 \%)$, plagioclasa (10-15\%), moscovita $(30-35 \%)$, minerales menores de paligorskita, greigita y pirita, y minerales secundarios de alunita, sericita (de plagioclasa) y caolín (de feldespato potásico). La greigita, no fue distinguible por calcografía, sino por difracción de rayos X (Tabla 2). Los cristales de paligorskita que presentan en la roca, son producto de la alteración de la los cristales de plagioclasa, como una variedad de mica blanca, y se encuentra generalmente asociada o en contacto con la moscovita (Figuras 7e y 7f). La denominación de alaskita es atribuida a su color claro característico, el cual es apreciable en los sitios donde aflora. La roca corresponde a un monzogranito, el cual presenta cuarzo (50-55\%), feldespato potásico (25-30\%) y plagioclasa $(20-25 \%)$. 

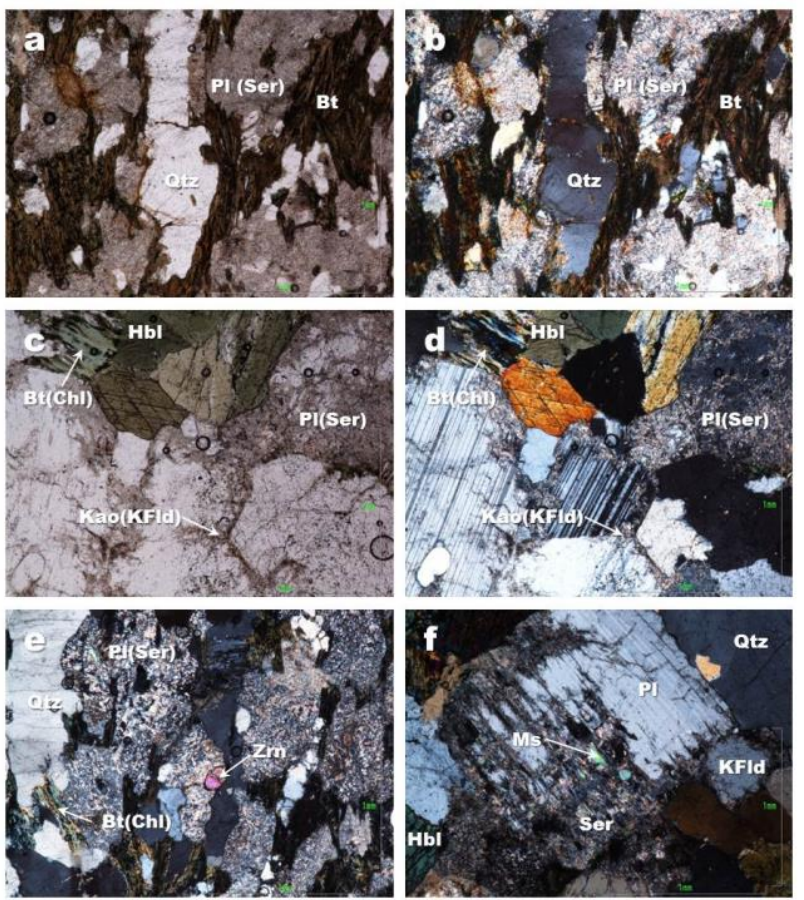

Figura 6. Petrografía, roca metamórfica, neis biotítico. a) Cuarzos alargados, biotitas alineadas y algo alteradas, objetivo 5X, nicoles paralelos. b) Alteración de la plagioclasa a sericita y biotita a clorita, texturas lepidogranoblásticas y poiquilobrlástica, objetivo 5X, nicoles cruzados. c) Circón relacionado con cuarzo y plagioclasa alterada a sericita, objetivo 5X, nicoles cruzados. Roca ígnea, granodiorita. d) Cristales de clinozoicita provenientes de la alteración de la plagioclasa, objetivo 10X, nicoles cruzados. e) Cuarzo, plagioclasa, hornblenda, biotita alterando a clorita, sericita de la alteración de la plagioclasa, feldespato potásico y este mismo alterando a caolín y en el centro un cristal de esfena, objetivo 5X, nicoles paralelos. f) Figura anterior en nicoles cruzados, se observar un cristal de cuarzo incluido en un cristal de plagioclasa. 

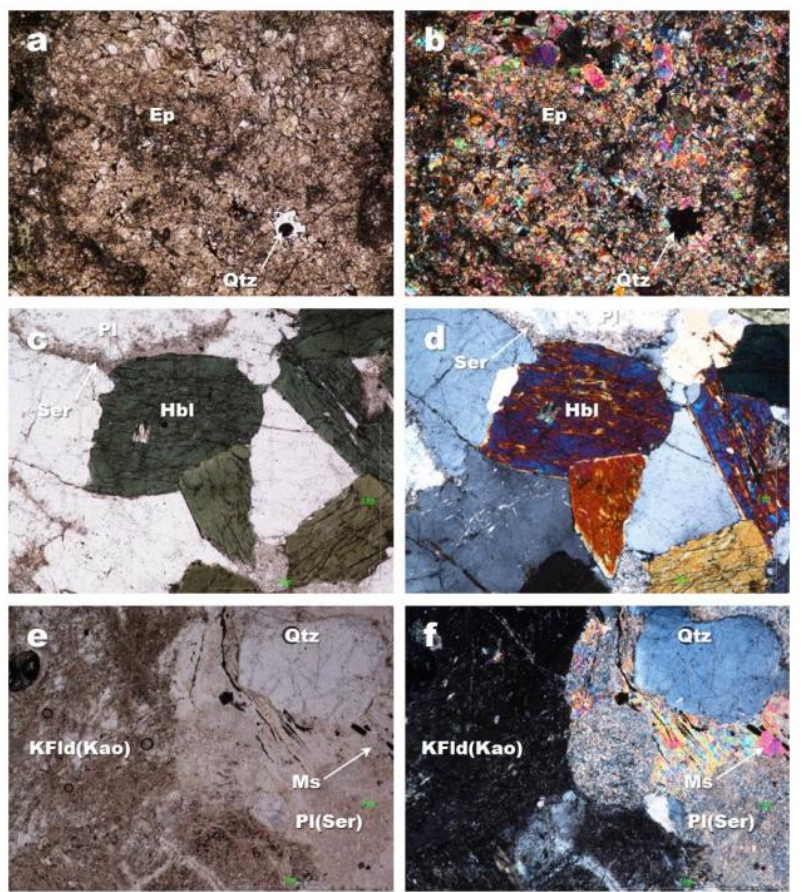

Figura 7. Petrografía, roca ígnea, granodiorita. a) Vena epidotizada, objetivo 5X, nicoles paralelos. b) Vena epidotizada, objetivo 5X, nicoles cruzados. c) Textura poikilítica, un cristal de biotita incluido en uno de hornblenda, objetivo 10X, nicoles paralelos. d) Figura anterior nicoles cruzados. e) Color claro de la alaskita por su composición de cristales como cuarzo, plagioclasa, feldepato potásico y moscovita, objetivo $5 \mathrm{X}$, nicoles paralelos. f) Cristal de paligorskita en contacto con moscovita, también se pueden apreciar cristales de cuarzo, plagioclasa alterando a sericita y feldespato potásico alterando a caolín, objetivo $5 \mathrm{X}$, nicoles cruzados.

Tabla 2. Resultado del análisis de difracción de rayos $\mathrm{X}$ de roca ígnea, alaskita.

\begin{tabular}{|c|c|c|c|c|}
\hline \multicolumn{2}{|r|}{ FASE } & $\begin{array}{l}\text { No. TARJETA } \\
\text { PDF-2 }\end{array}$ & NOMBRE & CUANTITATIVO \\
\hline \multirow{7}{*}{ Cristalinos } & $\mathrm{SiO}_{2}$ & $010-75-8321$ & Cuarzo & $33.3 \%(\mathrm{D} . \mathrm{E}=0.2)$ \\
\hline & $\mathrm{KSi}_{3} \mathrm{AlO}_{8}$ & $010-71-1540$ & Ortoclasa & $15.6 \%(\mathrm{D} . \mathrm{E}=0.2)$ \\
\hline & $\mathrm{Mg}_{5}\left(\mathrm{Si}_{4} \mathrm{O}_{10}\right)_{2}(\mathrm{OH})_{2}\left(\mathrm{H}_{2} \mathrm{O}\right)_{8}$ & $010-88-1950$ & Paligorskita & $2.7 \%(D . E=0.1)$ \\
\hline & $\mathrm{KAl}_{2} \mathrm{Si}_{3} \mathrm{Al} \mathrm{O}_{10}(\mathrm{OH})_{2}$ & $010-78-1928$ & Moscovita & $30.8 \%$ (D.E $=0.2)$ \\
\hline & $\mathrm{Fe}_{3} \mathrm{~S}_{4}$ & $010-89-1998$ & Greigeita & $0.6 \%(D . E=0.1)$ \\
\hline & $\mathrm{KAl}_{3}\left(\mathrm{SO}_{4}\right)_{2}(\mathrm{OH})_{6}$ & $000-47-1884$ & Alunita & $1.9 \%(D . E=0.1)$ \\
\hline & $\mathrm{FeS}_{2}$ & $010-71-1680$ & Pirita & $0.2 \%(D . E=0.1)$ \\
\hline \multicolumn{4}{|c|}{ Total Cristalino } & $85.1 \%$ \\
\hline \multicolumn{4}{|c|}{ Amorfos y otros } & $14.9 \%$ \\
\hline
\end{tabular}

\section{Mineralización}

En La Mina La Baja se han realizado dos laboreos de explotación en lugares diferentes, cada uno de estos laboreos se han desarrollado posiblemente sobre mineralizaciones diferentes, la primera de ellas se llevó a cabo en los ya nombrados túneles abandonados de la mina, ubicados sobre la vía que conduce a la vereda 
79

Angosturas, la mayoría de ellos, frente a las instalaciones del casino y planta de beneficio de la misma, de los cuales ha sido imposible tomar datos y muestra, pues en todos ellos es prohibida la entrada ya que estos superan los 10 años de abandono; y fuera del abandono de estas labores, no hay un estudio que permita corroborar el tipo de mineralización, la única fuente de información proviene de la administración de la mina, quienes afirman que en dichas explotaciones de hecho, la mineralización era filoniana, pero se desistió del avance porque en algunos túneles se perdió la continuidad de las vetas y en otros hubo advertencia de subsidencia. De acuerdo al sector donde están ubicadas estas labores antiguas, se realizaban atravesando la alaskita, a diferencia de las actuales labores en el túnel Ventanas, donde la roca caja es la granodiorita, por esta información y la información de una mineralización filoniana, es que se puede hacer diferencia entre los dos tipos de mineralización, pero finalmente no hay datos concretos que corroboren esto. En el caso del túnel Ventanas, se puede identificar una estructura brechificada, con una potencia considerable en su emplazamiento, desprendiendo fragmentos de la roca encajante que corto, donde se observan xenolitos en su estructura, en algunos lugares con mayor evidencia (Figura 8a). Al atravesar o recorrer los niveles del túnel Ventanas, también se puede reconocer la posible dirección de emplazamiento, que como se anotó en el subcapítulo de la geología estructural, puede estar condicionado estructuralmente dicho emplazamiento por la falla de La Baja que controla el sector. En su mineralogía esta brecha está compuesta por minerales principales como cuarzo, moscovita, pirita, dolomita, minerales accesorios como hubnerita (wolframita), greigita, escorodita, circón, calcita y paligorskita, y minerales secundarios como alunita, jarosita y natrojarosita. Cada uno de estos minerales se encuentran asociados en la estructura brechificada, pero no presentan una continuidad en toda la misma, a excepción del cuarzo la alunita y la jarosita, que se encontraron en todas las muestras analizadas, en sección delgada y en XRX. Tantos los frentes de explotación como las paredes y techo del túnel, presentan un color marrón óxido, esto debido a la alteración superficial que presentan los sulfuros de hierro presentes, por el contacto de estos con el agua que constantemente fluye por toda la estructura, este color o alteración superficial, no permite la clara identificación de los minerales en campo o en los frentes ya explotados, tan solo en los frentes donde se presenta constantemente explotación es posible encontrar los techos y las paredes sin esta alteración, aunque no por mucho tiempo, pues el flujo constante del agua produce la alteración en muy corto tiempo (Figura 8b). Como se anotó anteriormente, el cuarzo está presente en todas las muestras analizadas, además, también es el mineral más abundante (Tabla 3), y se presenta en dos generaciones, una primera generación de cuarzo anhedral, generalmente asociado a los minerales opacos y a las micas, y una segunda generación de cuarzo amorfo, a manera de matriz afanítica, generalmente asociado a los minerales de alteración (Figuras 9a y $9 d)$. Las micas presentes en la mineralización son, micas claras, moscovita y 
80

paligorskita, estas se encuentran generalmente agrupadas y no presentan alteración (Figura 9b), los minerales opacos son sulfuros de hierro, el más común es la pirita, que no solo puede ser encontrada en asociaciones con los otros minerales que componen la brecha, sino agrupada en venas o sin ninguna geometría en especial (Figura 8c).

Tabla 3. Porcentaje de contenido mineralógico en las muestras analizadas del túnel Ventanas por difracción de rayos $\mathrm{X}$.

\begin{tabular}{cccccc}
\hline Mineral & \%G.3-M1A & \% G.3-M1B & \%G.4-M3 & \%G.5-M5A & \%G.5-M5B \\
\hline Cuarzo & 76,8 & 81,3 & 29,1 & 69,5 & 41,5 \\
Muscovita & & & 28,4 & & 6,1 \\
Pirita & 3,7 & & & 2,7 & 1,1 \\
Calcita & & & & 0,4 \\
Dolomita & & N.C. & 3,1 & \\
Circón & 0,4 & & & & \\
Hubnerita & 1,8 & & & & 0,2 \\
Greigita & & N.C. & & & \\
Escorodita & & 6,0 & & & \\
Paligoskita & & & 2,9 & & \\
Alunita & 2,6 & 2,5 & 27,9 & 20,7 & 33,0 \\
Jarosita & & 3,0 & 3,2 & 0,8 & 0,5 \\
Natrojarosita & 1,3 & & & & \\
\hline
\end{tabular}
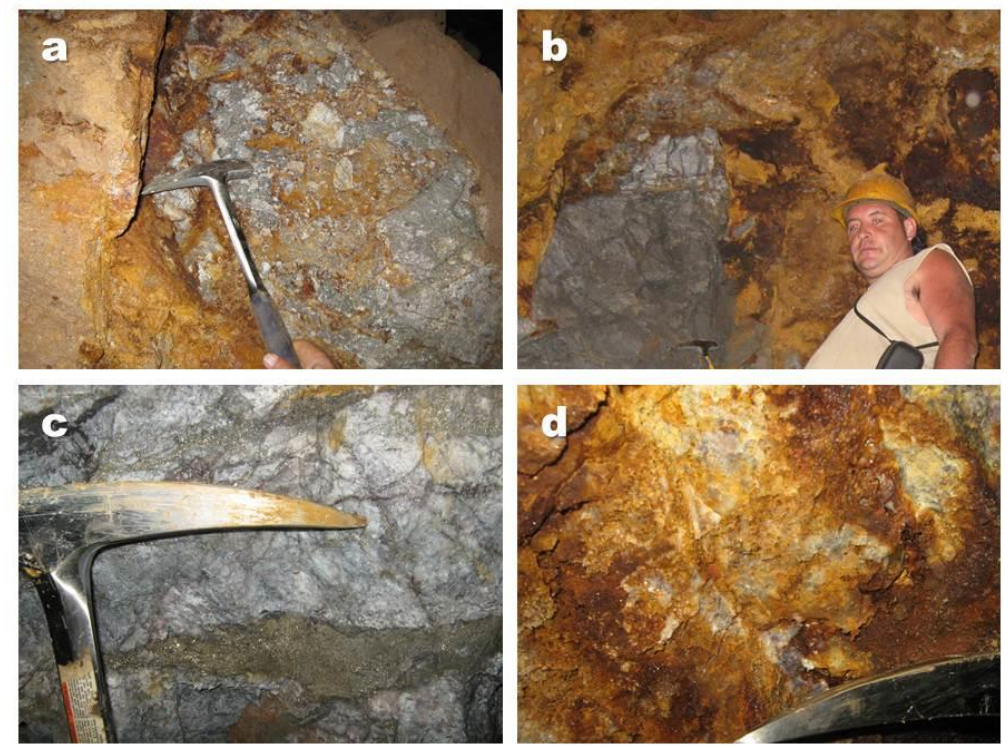

Figura 8. Mineralización del túnel Ventanas. a) Estructura y textura brechificada, se aprecia un sector con abundantes xenolitos de la roca caja. b) Alteración superficial de los sulfuros de hierro por el agua presente (color marrón oxido), se observa una sección fresca sin alteración (color gris), frente 2. c) Agrupación de pirita en venas, rellenando las fracturas de la brecha mineralizada. d) Porosidad característica de la brecha mineralizada, se presenta una textura arenosa de color azulado, correspondiente a la alunita. 


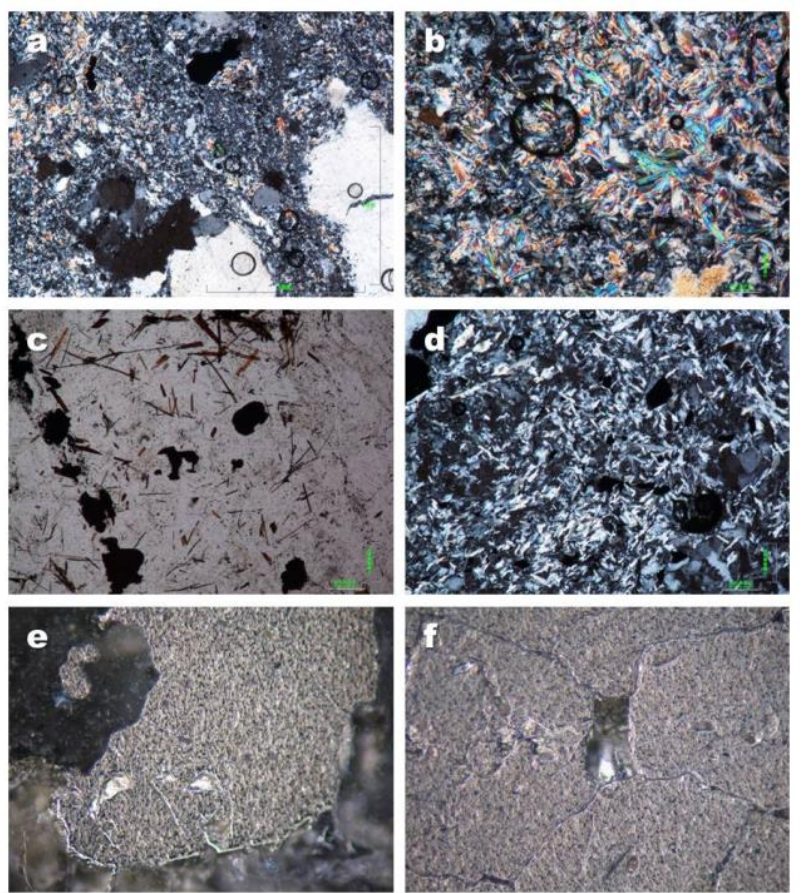

Figura 9. Mineralización. a) Cuarzo anhedral, asociado a minerales opacos, se puede apreciar un circón en el centro, objetivo 5X, nicoles cruzados. b) Cristales de moscovita y paligorskita asociados al cuarzo, objetivo 10X, nicoles cruzados. c) Cristales de jarosita asociados a cuarzo y minerales opacos de sulfuro de hierro (posiblemente pirita), objetivo 10X, nicoles paralelos. d) Alunita asociada a cuarzo amorfo, esta se observa de manera pseudo-acicular, objetivo 10X, nicoles cruzados. e) Oro incluido en pirita, objetivo 10X. f) Plata incluida en pirita, objetivo 10X.

A estos minerales opacos o sulfuros de hierro, está asociado el oro y la plata que se explota según estudios realizados en las otras mineralizaciones del sector (Díaz y Guerrero, 2006), el oro y la plata presentes en esta mineralización del túnel Ventanas, han sido catados o medidos a través de ensayes a fuego realizados a muestras de todos los frentes de explotación de este túnel, análisis que no muestra la asociación directa de estos minerales. En el análisis calcográfico realizado a las secciones pulidas, también se observó la relación entre oro-pirita y plata-pirita, solo fue posible identificar esta asociación con cristales de pirita, en algunos casos bastante alterada, no se halló relación directa entre el oro y la plata, pero si en cuanto a su presencia, pues solo se encuentran en las agrupaciones de los sulfuros (Figuras 9e-9f). La hubnerita no tampoco se identificó en calcografía, solo por difracción de rayos $\mathrm{X}$, este mineral está presente generalmente en zona hipotermales (Garcés, 1984), lo que indica la potencia del emplazamiento al extraer xenolitos o minerales de esa profundidad. La jarosita es uno de los minerales secundarios o de alteración presentes en esa brecha mineralizada, se cuantificó en cuatro de los cinco análisis de difracción de rayos $X$ que se realizaron a la brecha mineralizada, tan solo en una muestra no se cuantificó, pero si se cuantificó la 81 
82

natrojarosita, que en su polimorfo cuando se reemplaza el potasio por el sodio (Figuras 10a-10b). La presencia de estos minerales de alteración (jarosita y natrojarosita), siendo estos pseudomorfos de la pirita, se encuentra asociada a los cristales opacos, más no se muestra como una alteración de estos minerales (Figura $9 c)$. El mineral de alteración que más se presenta en la brecha mineralizada es la alunita, este se encuentra asociado generalmente al cuarzo, y si se considera la relación entre estos dos con respecto al porcentaje de contenido en cada una de las muestras analizadas, se puede deducir que a medida que el contenido de cuarzo disminuye, el contenido de alunita aumenta (Figura 11); conociendo que el cuarzo no es un mineral que altere, y que los cristales de cuarzo que están asociados a la alunita son generalmente los amorfos de la matriz, se puede deducir que la alteración a alunita que presenta la brecha hidrotermal, recristalizo en los lugares donde el cuarzo no lo hizo, ocupando sus espacios.
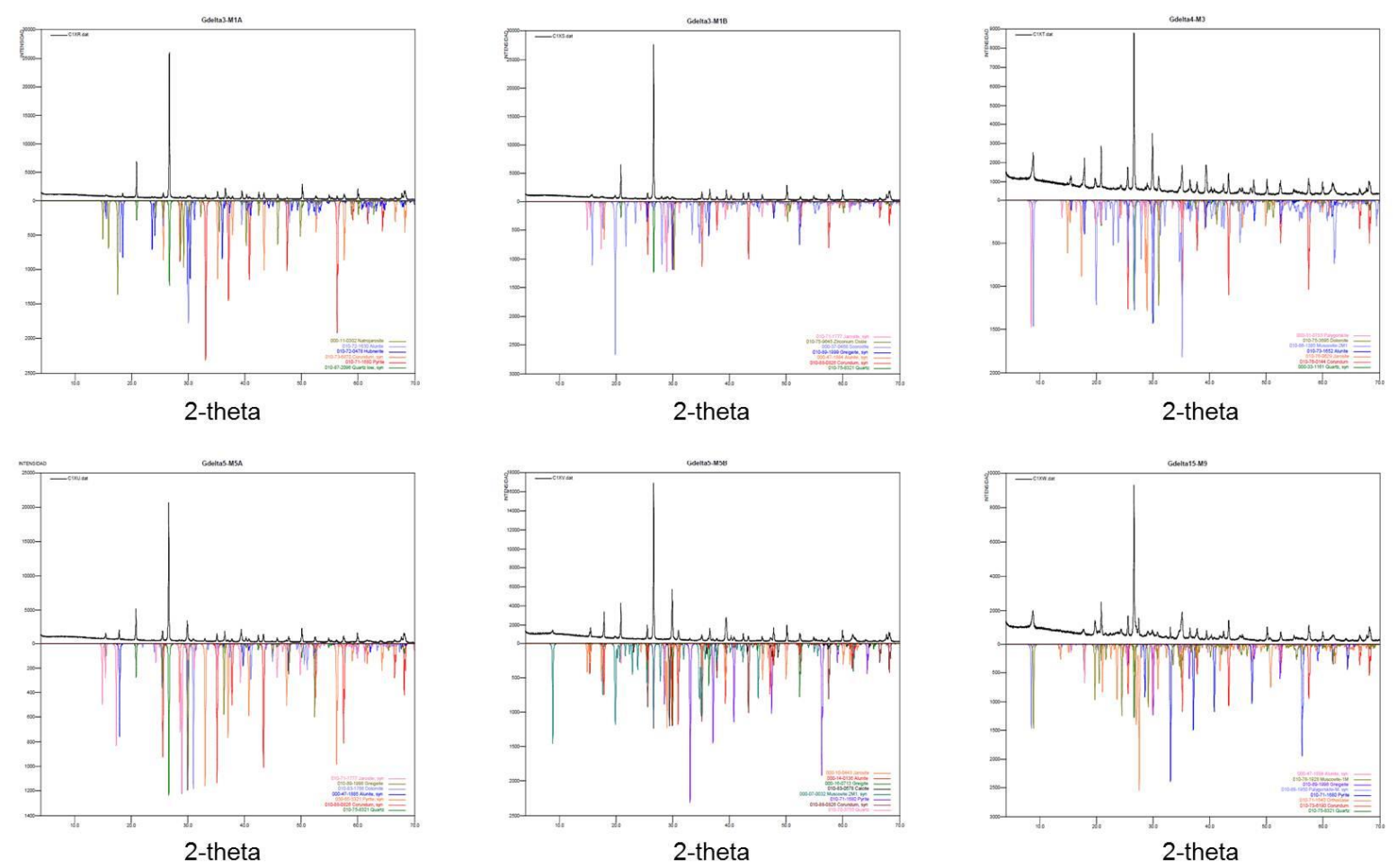

Figura 10. Diagramas de fase de las muestras analizadas por difracción de rayos $\mathrm{X}$. 


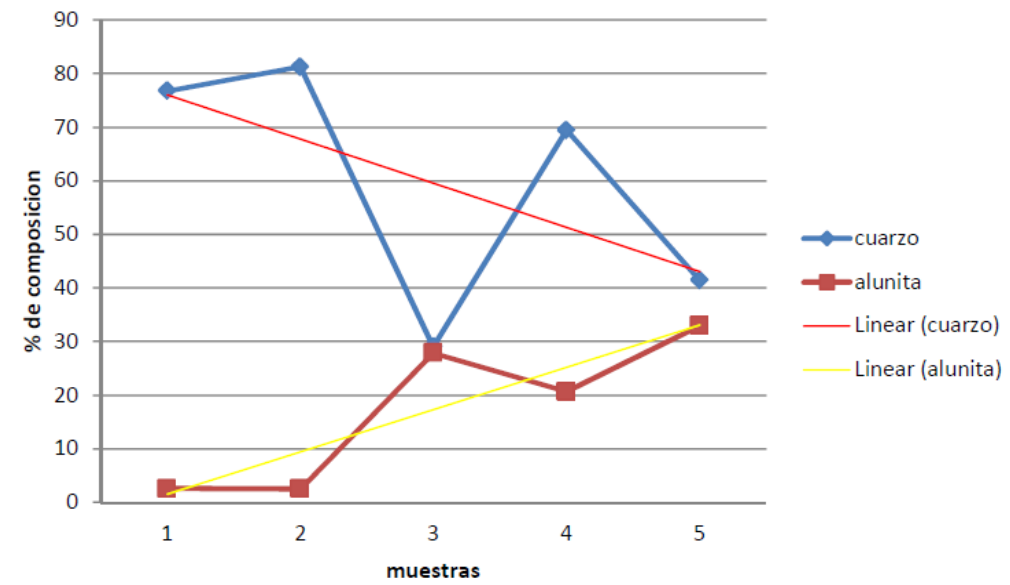

Figura 11. Tendencia composicional del cuarzo y la alunita en las muestras analizadas de la brecha mineralizada del túnel Ventanas.

De las muestras que se analizaron tanto con difracción de rayos $X$ como con mineralogía óptica, aquellas donde se evidenciaba una porosidad característica en toda la brecha mineralizada, arrojaron mayor de contenido de alunita, estos cristales le dan a la textura porosa de la brecha, una textura algo sacarosa o arenosa de color azulado (Figuras $8 \mathrm{~d}$ y $8 \mathrm{~d}$ ). La alunita es un mineral presente generalmente en alteraciones de sistemas magmático-hidrotermales, de los cuatro posibles ambientes de formación de la alunita, la que se presenta en la brecha mineralizada corresponde a la supergena, que se desarrolla a partir de la producción de ácido sulfúrico por la meteorización de sulfuros, formando $(\mathrm{K}, \mathrm{Na}) \mathrm{Al}_{3}\left(\mathrm{SO}_{4}\right)_{2}(\mathrm{OH}) 6$ que involucra la introducción de $\mathrm{S}$ y $\mathrm{H}_{2} \mathrm{O}$ y la remoción de $\mathrm{Si}, \mathrm{Na}, \mathrm{Ca}, \mathrm{Mg}$ y $\mathrm{Fe}$, como ocurre en el caso de la brecha mineralizada del túnel Ventanas, además, la forma del mineral en estos casos es pseudo-acicular y se asocia otros minerales supergénicos como hematita y jarosita, esta última presente en la mineralización de la brecha, característico de la alunita supergénica. Este tipo de mineral está presente en la alteración de rocas ácidas, roca caja de la brecha mineralizada (granodiorita), y se cristaliza junto con el cuarzo por alteración de feldespatos, formando así la alteración conocida como alunitización, que por su gran contenido en el cuerpo mineralizado, es posible que se esté presentando como la alteración en la zona de la brecha o en la brecha como tal. Según uno de los modelos para sistemas magmático-hidrotermales presentes en márgenes de placa, propuesto por Giggenbach (2003), la alunitización se produce en sistemas de depósitos de alta sulfuración y no se produce a más de $1 \mathrm{~km}$ de profundidad (Figura 12). 


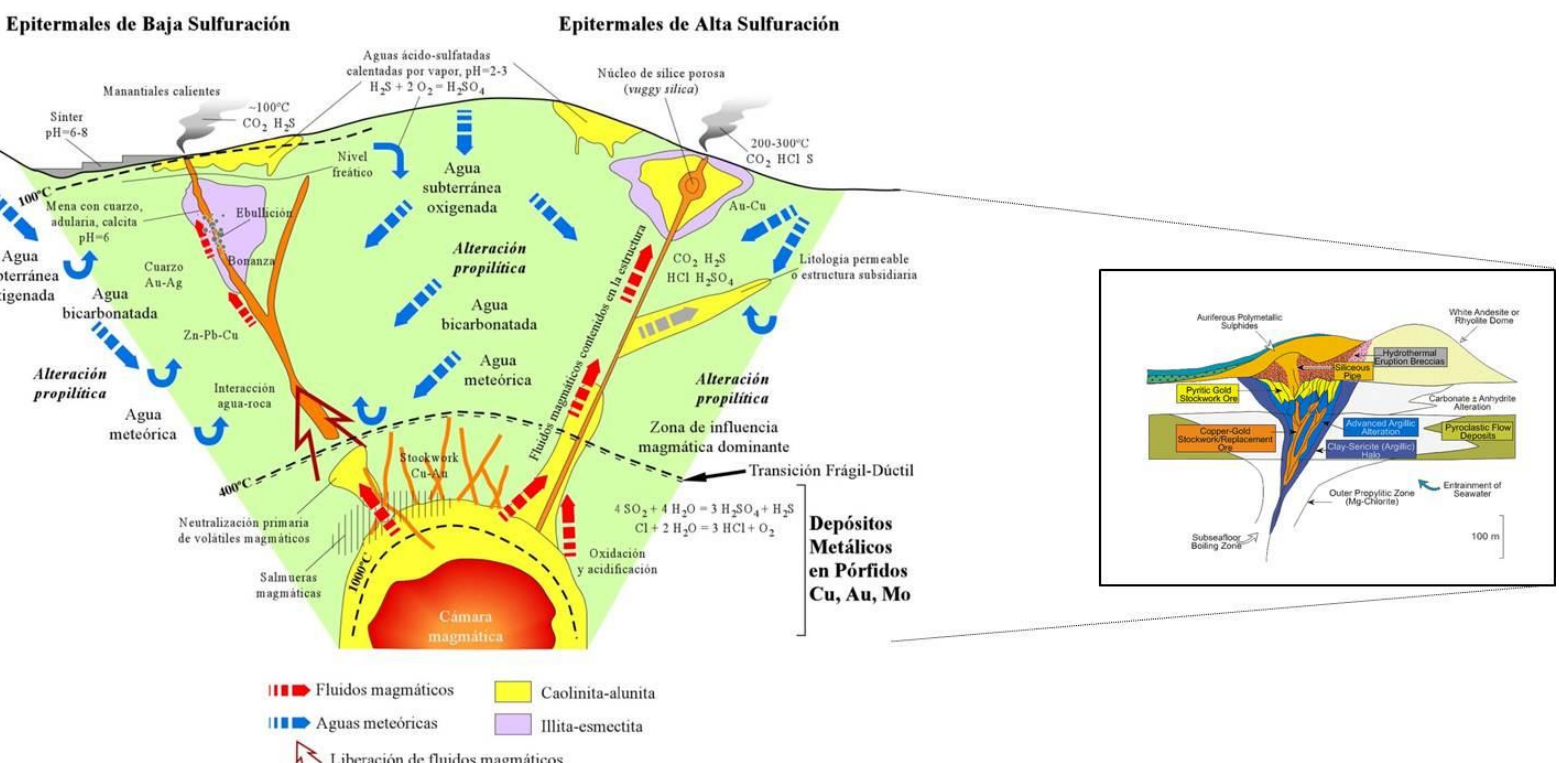

Figura 12. Modelo de alta y baja sulfuración y sus alteraciones, sistemas magmáticohidrotermal en márgenes de placa. Tomado de Giggenbach (2003).

En este modelo, la alteración alunítica, se produce en sistemas de alta sulfuración, y en el caso del depósito auroargentífero de California, se le ha reconocido como un depósito de alta sulfuración, y sin pretender enmarcar la brecha mineralizada en un modelo sistemático, pues no hay datos suficientes para esto, se puede reconocer una similitud con el tipo de alteración de dicho modelo propuesto por Giggenbach (2003). Partiendo de que este tipo de mineral se hace presente es sistemas magmático-hidrotermales, la brecha mineralizada puede ser encajada o denominada como una brecha mineralizada de tipo hidrotermal o una brecha hidrotermal. La mineralización de la brecha hidrotermal del túnel Ventanas, no se puede correlacionar directamente con ninguna de las otras mineralizaciones o brechas del distrito en el municipio de California, la razón para no hacerlo, es la diferencia entra los minerales mena y los minerales ganga, que en los casos de los estudios en otras áreas del distrito, han evidenciado desde dos hasta cuatros distintos tiempos de paragénesis o formación, cada uno de estos con una asociación mineral específica y diferente de la otra, pero ninguna de estas asociaciones es igual o similar a la presente en dicho túnel, aunque la mayoría de estos minerales están presentes en las otras mineralizaciones, por lo tanto se marca una distancia considerable entre la paragénesis o metalogenia de estas, distinguiendo que la asociación mineral de la brecha hidrotermal del túnel Ventanas es: Minerales mena: oro + plata + pirita + greigita + escorodita; Minerales ganga: cuarzo + moscovita + paligorskita + calcita + dolomita + circón + hubnerita 


\section{Discusión sobre metalogenia y diseño}

Para analizar un marco tectónico de algún yacimiento o depósito mineral, hay que tener o realizar una serie de análisis que permitan obtener detalles precisos 0 concisos de su emplazamiento, dichos análisis no fue posible realizarlos para este estudio, por lo cual no hay los suficientes datos para concluir un marco tectónico en este caso. A pesar de no contar con los datos necesarios para enmarcar es esta mineralización en un panorama de sus génesis, hay algunos datos obtenidos que permiten proponer o acercarse a un marco tectónico posible para este yacimiento, sin intentar llegar al atrevimiento o demasiada osadía para esto, pues lo que se quiere es tratar de dar una idea de la posibles condiciones que permitieron este emplazamiento o tipo de mineralización. Las brechas hidrotermales, se presentan en los sistemas magmático-hidrotermales, sistema al cual se ha encasillado esta brecha por su contenido mineralógico y estructural, dichos sistemas constan de una serie de zonas marcadas donde se presentan diferencias en el yacimiento, estas diferencias son producto de la profundidad de su formación, donde su textura y mineralogía cambian considerablemente, desde un ambiente hipotermal hasta un ambiente epitermal, pasando por un ambiente mesotermal (Garcés, 1984). Según Sillitoe (2000), las brechas hidrotermales están asociadas comúnmente a sistemas de depósitos de pórfidos, y su emplazamiento se puede producir tanto temprana como tardíamente (Figura 13a), aunque en sistemas de pórfidos ricos en oro, estas brechas se producen relativamente temprano, y son activadas producto de descargas de fluidos de una fase intermineral del pórfido. Según este mismo autor, estas brechas pueden solaparse en un estado final del sistema con un estado final de la alteración argílica asociado a una mineralización epitermal de alta sulfuración (Figura 13b). Estos sistemas de alta sulfuración, se producen en sistemas magmático-hidrotermales de margen de placa. En el distrito minero de VetasCalifornia se han cartografiado y datado los pórfidos presentes, dichos pórfidos no contienen mineralógicamente oro hasta donde se conoce, aun así, su datación ha sido de 8,4 $\pm 0,2$ y 9,0 $\pm 0,2 \mathrm{Ma}$ (Mantilla et al 2009), lo que permite relacionar estas edades con los sucesos geológicos de ese tiempo. Según Toussaint (1999), para el mio-plioceno, las placas oceánicas Nazca y Caribe colisionaban con la placa Suramericana, en medio de estas se encontraban los Andes septentrionales, que actualmente es un bloque en cuña que separa estas placas, todas ellas subduciendo a este. Si se tiene en cuenta el choque de las placas oceánicas con la continental para esa edad, es posible que el margen de placas de las primeras presentara subducción sobre la segunda, y que el magmatismo producido por esta acción, fuera el responsable de los pórfidos encontrados y datados en la región de VetasCalifornia. 

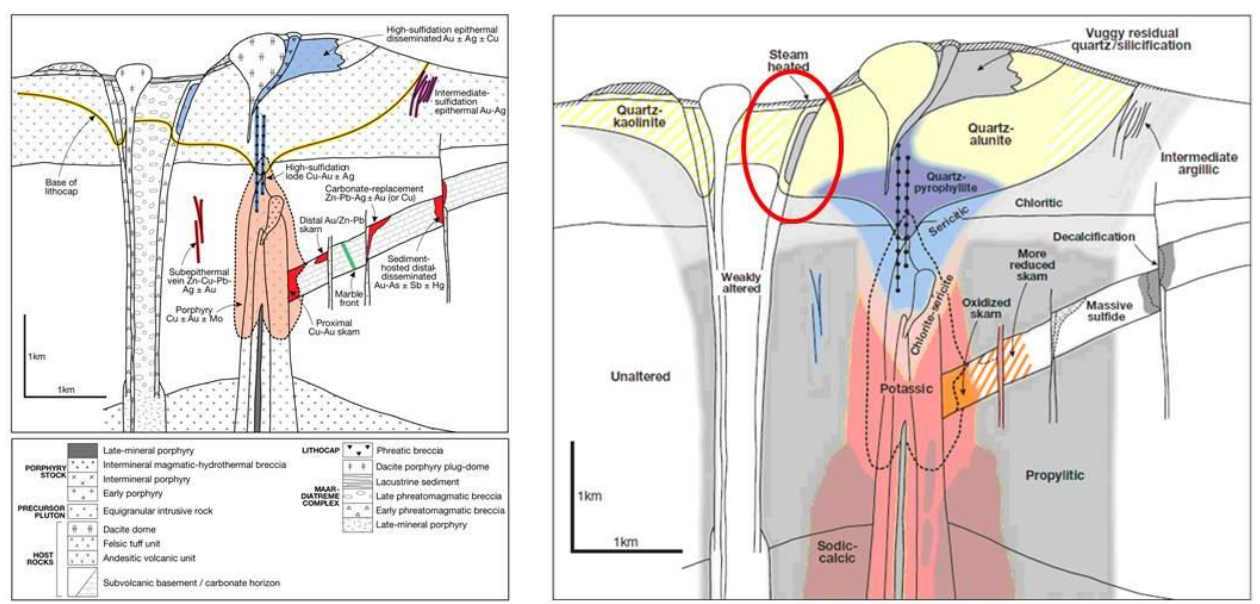

Figura 13. Sistema magmático-hidrotermal de pórfidos de Cu según Sillitoe (2010). (a) Relación espacial. (b) Zonas de alteración, en rojo área de solape.

Si se tiene en cuenta estos posibles sucesos en la región, se propone que la mineralización de la brecha hidrotermal del túnel Ventanas, fue producto de un sistema magmático-hidrotermal de margen de placa, debido a la colisión y subducción de las placas oceánicas (posiblemente por ubicación la placa Caribe) bajo la placa continental (placa Suramericana) en el mioceno tardío, este sistema general, originó un sistema de pórfido, y este es posiblemente el causante de esta brecha. Si la caldera volcánica (Galvis, 1998), ubicada de edad Terciaria (sin datación específica), perteneció a un volcán o estratovolcán, esto afianza un poco más el sistema de pórfido, pues en estos se pueden desarrollar los típicos sistemas magmático-hidrotermales propuestos por Sillitoe (2000) y Giggenbach (2003), además de las alteraciones fílicas y propílicas que se encuentran al interior de dicha caldera (Galvis, 1998). La alteración que contiene la brecha hidrotermal del túnel Ventanas, típica alteración epitermal alunítica, acompañada de cuarzo, es similar a la alteración detallada en el modelo de Sillitoe (2000), quien describe que la alteración argílica avanzada, también contiene esta alteración, y conociendo que esta se puede solapar con las brechas (Figura 13), es posible que sea la situación del túnel Ventanas, donde la alteración está presente en lo explorado de la brecha. En los modelos de Sillitoe (2000) y Giggenbach (2003) para estos sistemas magmático-hidrotermales, la alteración alunítica, solo se presenta en el primer kilómetro de profundidad del mismo, por lo tanto es posible concluir que las labores de explotación adelantadas en el túnel Ventanas, se encuentran ubicadas en la zona epitermal del sistema o de la brecha hidrotermal. Como se anotó en los objetivos de este estudio, el diseño que se presenta a continuación, no es un modelo final ni de la estructura mineralizante ni de su emplazamiento como tal, sino una propuesta preliminar de las anteriores, esto a razón de no tener los datos ni contar con el tiempo suficiente para realizar un diseño de ese nivel. Para realizar este diseño 86 
87

preliminar, se tomaron en cuenta datos como la dirección de emplazamiento de la brecha, el espesor o diámetro que presenta esta mineralización en la superficie o área de explotación, la topografía del área correspondiente a la mina La Baja, los contactos geológico o la cartografía geológica local que se realizó, entre otros, además de tener en cuenta los diseños en 2D propuestos por Sillitoe (2000) para este tipo de brechas. Partiendo de la cartografía geológica, la topografía en 2D y teniendo en cuenta cada uno de los espacios determinados, se trazaron los contactos geológicos curva a curva a través del área, se corrigió cada una de las curvas en elevación precisa gracias a puntos tomados con GPS submétrico, y se hizo la proyección de esto en 3D, en el software AutoCad-2010 (Figura 14).
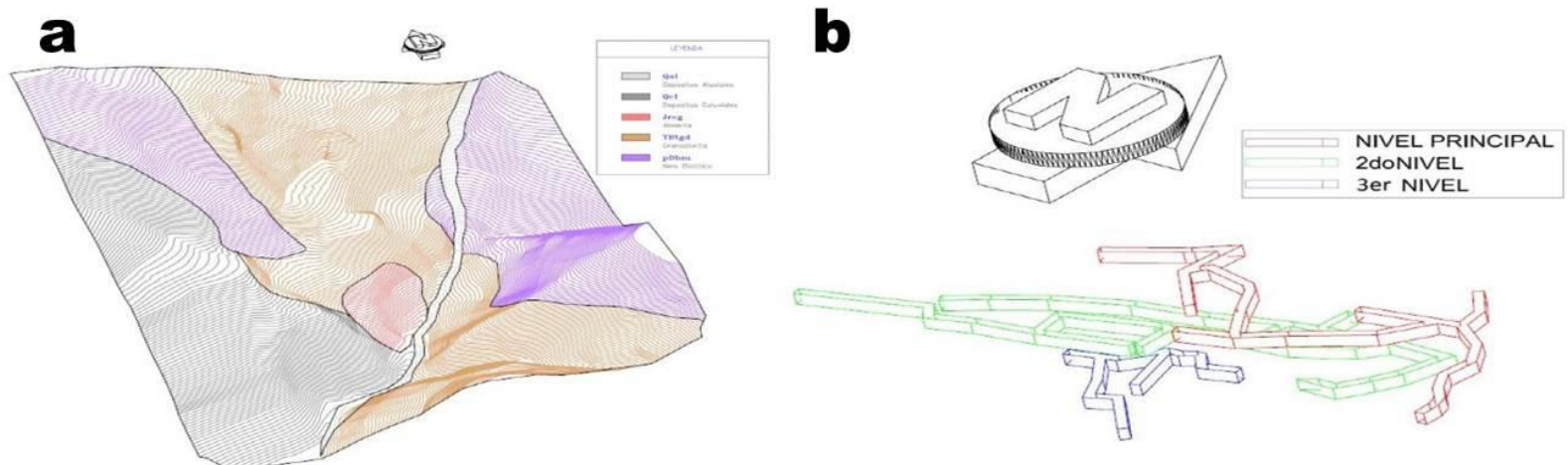

Figura 14. Izquierda, diseño en 3D de la topografía del área de la mina La Baja. Derecha, Diseño en 3D del túnel ventanas. Software AutoCad-2010.

Los trazos del túnel Ventanas, se realizaron con toma de medidas de dirección, longitud, clavadas en ángulos para cada uno de los niveles, estos datos están actualizados al mes de marzo de 2010 , el espesor de los túneles o pasillos varía desde 2 hasta $5 \mathrm{~m}$ de ancho, y de 1,6 hasta $5 \mathrm{~m}$ de altura, dependiendo del sector de frentes, cruzadas y pasillos, para este diseño preliminar se tuvo en cuenta un promedio de $2 \mathrm{~m}$ de ancho por $2 \mathrm{~m}$ de altura, pues esta medida es la promedio en el recorrido del túnel. Reconociendo que no se tienen perforaciones o datos de perforaciones para hacer un seguimiento a la brecha hidrotermal del túnel Ventanas, se tuvo en cuenta el modelo en 2D de Sillitoe (2000) para sistemas de pórfidos y brechas hidrotermales, se trazó la posible estructura de la brecha en 2D, o por lo menos los $200 \mathrm{~m}$ superficiales de esta, dado que la altura mínima y máxima en cota del área de la mina La Baja, tiene una diferencia de aproximadamente $200 \mathrm{~m}$; luego de tener el diseño de la estructura en 2D, se tomaron en cuenta cada uno de los trazos de esta para pasarla a una estructura en 3D, dándole una inclinación hacia el NW-SE, dirección en la cual se ha emplazado (Figura 15a). Como se anotó anteriormente, no hay un seguimiento con perforaciones a esta estructura, tan solo el que se le puede hacer a través del túnel Ventanas, por esta razón no se diseñaron los contactos de esta brecha en profundidad, pues el único dato reconocido es su roca caja en superficie, la granodiorita, mas no se conoce si en profundidad intruye 
88

alguna roca más. Como el modelo presentado, es una propuesta preliminar del posible emplazamiento y condicionamiento de la brecha hidrotermal del túnel Ventanas, mas no un diseño final, se ubicó el diseño del túnel en 3D, a la altura y posición correspondiente en el diseño de la cartografía geológica en 3D; luego se realizó lo mismo con el diseño en 3D de la estructura brechificada, teniendo en cuenta que el diámetro de esta no supera los $100 \mathrm{~m}$ de diámetro, y que no aflora en superficie, de esta mañera poder ver en el diseño la contextualización geológica de la brecha. Esto permite visionar o hacer una idea de cómo está dispuesta espacialmente la brecha hidrotermal, para que en estudios futuros se tenga una partida en la dirección de las investigaciones de la mina La Baja, propósito de este diseño o propuesta preliminar (Figuras 15b-15d).

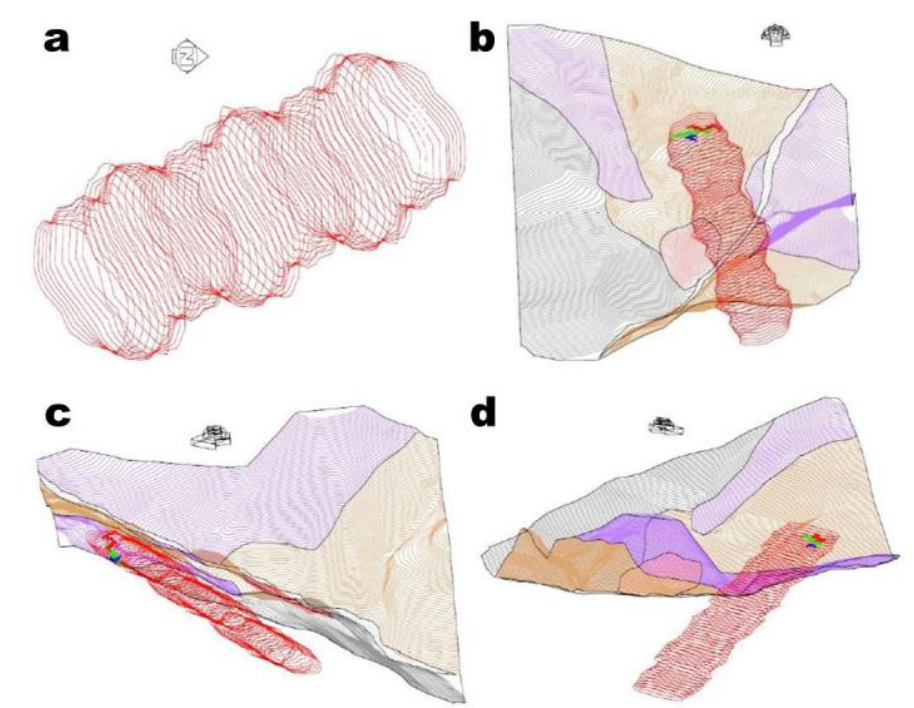

Figura 15. Diseño preliminar. a) Estructura de la brecha hidrotermal en 3D. b) Contextualización geológica de la brecha hidrotermal vista desde superficie en dirección NS. c) Contextualización geológica de la brecha hidrotermal vista desde superficie y profundidad en dirección NE-SW. d) Contextualización geológica de la brecha hidrotermal vista desde superficie y profundidad en dirección E-W. Software AutoCad-2010.

\section{Conclusiones}

En el área de la mina La Baja, afloran rocas metamórficas, de metamorfismo regional, correspondiente a un neis biotítico, compuesto por minerales principales como cuarzo, plagioclasa, biotita, moscovita, feldespato potásico, minerales secundarios como clorita (de la biotita), sericita (de la plagioclasa) y caolín (del feldespato potásico), y minerales accesorios como circón y corindón. Este neis es correlacionable con el neis migmatítico del pre-Devónico descrito en la leyenda. Las rocas ígneas que afloran en el que se presentan en el área de la mina La Baja, 
89

corresponden a una granodiorita compuesto por minerales principales de cuarzo, plagioclasa, feldespato potásico, hornblenda, biotita, minerales menores como moscovita, epidota, clinozoicita y opacos, minerales accesorios como esfena y apatito y minerales secundarios como clorita (a partir de biotita y hornblenda), sericita (de plagioclasa) y caolín (de feldespato potásico). Otra roca ígnea aflorante en el área de la mina La Baja es una alaskita compuesta por minerales principales de cuarzo, feldespato potásico, plagioclasa, moscovita, minerales menores de paligorskita, greigita y pirita, y minerales secundarios de alunita, sericita (de plagioclasa) y caolín (de feldespato potásico). Estas rocas se correlacionan con los granitos del Jura-Triásico descritos en la leyenda. En el área de la mina La Baja, se encuentran depósitos cuaternarios de tipo coluvión y de tipo aluvión. Estructuralmente, el área de la mina La Baja, está condicionada al igual que el distrito minero de California, por el lineamiento producido por la falla de La Baja, con dirección NE, falla satélite de la falla regional de Cucutilla, perteneciente a un sistema de compresión. Las mineralizaciones presentes en el distrito minero de California, están condicionadas estructuralmente por la falla de La Baja, con emplazamientos en dirección NW. La mineralización de la mina La Baja, que se encuentra en el túnel Ventanas, también se encuentra condicionada estructuralmente por la falla de La Baja, esta mineralización presenta una estructura brechificada, que se emplaza en la granodiorita en dirección NW. La asociación de la brecha mineralizada del túnel Ventanas, se compone por minerales mena de oro + plata + pirita + greigita + escorodita, minerales ganga de cuarzo + moscovita + paligorskita + calcita + dolomita + circón + hubnerita y minerales de alteración de alunita + jarosita + natrojarosita. La alteración alunítica, se encuentra en toda la mineralización, esta es característica de las alteraciones epitermales de un sistema magmático-hidrotermal (e.g., Giggenbach, 2003 y Sillitoe, 2000). La propuesta de una caldera volcánica (Galvis, 1998), perteneciente a un paleovolcán del Terciario, la datación de los pórfidos de la región con edades de 8,4 \pm 0,2 y 9,0 \pm 0,2 Ma (Mantilla, 2009), y el marco tectónico propuesto de colisión de placas para el MioPlioceno en este sector de la cordillera oriental (Toussaint, 1999), permiten concluir de manera preliminar que los pórfidos presentes fueron emplazados en un margen de placa, perteneciente a un sistema magmático-hidrotermal, y dichos pórfido o sistemas de pórfidos, posiblemente fueron los causantes de la mineralización presente en el túnel Ventanas de la mina La Baja, semejante al modelo de brecha hidrotermal (Sillitoe, 2000 y 2010). Las labores de explotación adelantadas en el túnel Ventanas de la mina La Baja, se desarrollan en la zona epitermal de la brecha hidrotermal. El modelo en 3D propuesto para la contextualización geológica de la brecha hidrotermal de la mina La Baja, se presenta como un modelo preliminar totalmente sujeto a modificaciones. 


\section{Trabajo futuro}

Formalizar un estudio en detalle de cada una de las familias de diaclasas presentes en el interior del túnel Ventanas, con el propósito de identificar con mayor exactitud la dirección de emplazamiento de la brecha hidrotermal, datos de gran utilidad a la hora de continuar la cruzadas de explotación y de decidir un posible trabajo de perforaciones. Para complementar el estudio estructural de la brecha hidrotermal, hacer un seguimiento a las diaclasas que presenta las rocas que afloran en el área, en especial la roca caja, para obtener un modelo estructural y su relación con el emplazamiento de la brecha. Obtenido un estudio completo del modelo estructural de diaclasa del área y en especial de la brecha hidrotermal, realizar un trabajo de perforaciones con recuperación de núcleos para verificar la profundidad y continuidad de la misma. Si se quiere complementar el modelo preliminar, con el fin obtener un modelo final de la brecha mineralizada, es necesario un estudio completo de geoquímica y geofísica para identificar cada una de las relaciones de esta mineralización con el tipo de pulso que ocasionó su formación o emplazamiento, de igual manera su relación con las rocas intrusivas del área. Si se quiere es el modelo completo del yacimiento, el estudio debe estar unido con todo el distrito minero de California.

\section{Agradecimientos}

Esta investigación forma parte de la tesis de pregrado G.G. Contreras de la Universidad Industrial de Santander. Agradecemos al Laboratorio de Rayos X la Universidad Industrial de Santander y su personal para la adquisición y análisis de datos de difracción de rayos X. Los autores agradecen al geólogo José Luis Avella S. por su colaboración y gestión ante la Sociedad Minera La Baja California S.A.S. por proporcionar las facilidades para estudiar el túnel Ventanal y alrededores de la Mina La Baja. Agradecimientos también a los árbitros anónimos por su crítica y lectura detallada del manuscrito. Estamos muy agradecidos con las personas e instituciones nombradas anteriormente por su ayuda y colaboración.

\section{Referencias bibliogràficas}

Aceros, C.H., y Lamus, A. (1993). Estudio Geológico y Metalogénico de la Mina Barbacoas, California (Santander). Tesis de Grado. Universidad Industrial de Santander. Escuela de Geología. Bucaramanga.

Bissig, T., and Tosdal, R.M. (2009). Petrogenetic and Metallogenetic Relationships in the Eastern Cordillera Occidental of Central Peru. Journal of Geology 117: 499-518. 
Bueno, J. (1955). Yacimientos de Uranio y Otros Metales en la Región de La Baja. Boletín Geológico INGEOMINAS 3(3): 1-6.

Carvajal, L.C., y Rodríguez, E.D. (1975). Prospección Geofísica y Geoquímica en la Región de California (Santander). Geología Colombiana 9: 9-49.

Delgado, O. S., Aguilar, Z. S., Mesa, M. P., Díaz, S. B., \& Camargo, L. C. (2015). Estudio del comportamiento e impacto de la climatología sobre el cultivo de la papa y del pasto en la región central de Boyacá empleando los sistemas dinámicos. Study of the Behavior and Impact of the Weather on the Potato Crop and Pasture in the Central Region of Boyacá Using Dynamic Systems. CIENCIA EN DESARROLLO, 6(2), 215-224.

Clavijo, J. y Royero, J.M. (2001). Mapa geológico generalizado Departamento de Santander. Ingeominas, Memoria explicativa, Escala 1:400.000, 26-42.

Díaz, L.A., y Guerrero, M. (2006). Asociaciones Mineralógicas de las Menas Auroargentíferas y su Distribución Espacial en el Yacimiento Angosturas. Tesis de Grado. Universidad Industrial de Santander. Escuela de Geología. Bucaramanga.

Felder, G., Ortiz, G., Campos, C., Monsalve, I., y Silva, A. (2005). ANGOSTURA PROJECT, A High Sulfidation Gold-Silver Deposit located in the Santander Complex of North Eastern Colombia. Greystar Resources Ltd. Thech. Report. (http://www.greystarresources.com/i/pdf/Angostura_Greystar_ProExplo_2005Final.pdf).

Galvis, V.J. (1998). Una Caldera Volcánica en el Macizo de Santander. Revista Academia Colombiana de Ciencias 22(84): 355-362.

Goldsmith, R., Marvin, R., and Mehnert, H. (1971). Radiometric ages in the Santander Massif, eastern Cordillera, Colombian Andes, U.S. Geological Survey Professional Paper 750-D: D41-D49.

Garcés, H. (1984). Geología Económica de los Yacimientos Minerales y Yacimientos de Colombia. Ediciones Mapricol Ltda. Capítulo 9.

Giggenbach, W.F. (2003). Magma Degassing and Mineral Deposition in Hydrothermal System Along Convergent Plate Boundaries. Society Economic Geologist. Distinguished Lecture, Special Publication 10: 1-18.

Greig, D. (2009). Preliminary Feasibility Study, Technical Report NI 43-101. Angosturas Gold Proyect. GREYSTAR RESOURCES LTD.

Mantilla, L.C. (2009). Geocronología U-PB de los Cuerpos Porfiríticos del Distrito Auroargentífero de Vetas-California (Departamento de Santander, Colombia). Boletín de Geología 31(1): 31-43. 
Mantilla, L.C., Mendoza, H., Bissig, Th., y Craig, H. (2011). Nuevas evidencias sobre el magmatismo Miocénico en el Distrito Minero de Vetas-California (Macizo de Santander, Cordillera Oriental, Colombia. Boletín de Geología 33(1): 43-58.

Mendoza, H., y Jaramillo, L. (1979). Geología y Geoquímica del Área de California, Santander. Boletín de Geológico INGEOMINAS 22: 3-52.

91

Pérez, S., y Vargas, J. (1993). Geología y Geoquímica de los Yacimientos Filonianos de Oro en la Mina San Cayetano, Municipio de California (Santander). Tesis de Grado. Universidad Industrial de Santander. Escuela de Geología. Bucaramanga.

Pinto, E. (1991). Geología y evaluación de la Mina La Bodega, California (Santander). Tesis de Grado. Universidad Industrial de Santander. Escuela de Geología. Bucaramanga.

Pagnacco, P. (1962). Estudio Mineralógico del Filón Uranífero San Celestino. Geología Colombiana. Universidad Nacional de Colombia 1: 45.54.

Polanía, J.H. (1983). Mineralizaciones de Uranio y otros Metales en California (Santander). Geología Norandina 6: 57-65.

Sillitoe, R.H. (2000). Gold-Rich Porphyry Deposits: Descriptive and Genetic Models and Their Role in Exploration and Discovery. Society Economic Geologist 13: 315-345.

Sillitoe, R.H. (2010). Porphyry Copper Systems. Society Economic Geologist, Special Paper 105: 3-41.

Toussaint, J.F. (1999). Evolución Geológica de Colombia. Universidad Nacional de Colombia. Cap. Cenozoico 2. Bogotá.

Ward, D.E., y Goldsmith, R. (1970). Recursos minerales de parte de los Departamentos de Norte de Santander y Santander, Inventario Minero de Colombia. Boletín Geológico 18(NQ 3): $140 \mathrm{p}$.

Ward, D.E., Goldsmith, R., Cruz, B.J., Jaramillo, C.L., y Restrepo, H. (1973). Geología de los Cuadrángulos H-12, Bucaramanga y H-13, Pamplona, Departamento de Santander. U.S. Geological Survey e Ingeominas. Boletín Geológico XXI(1-3), 132p. 
